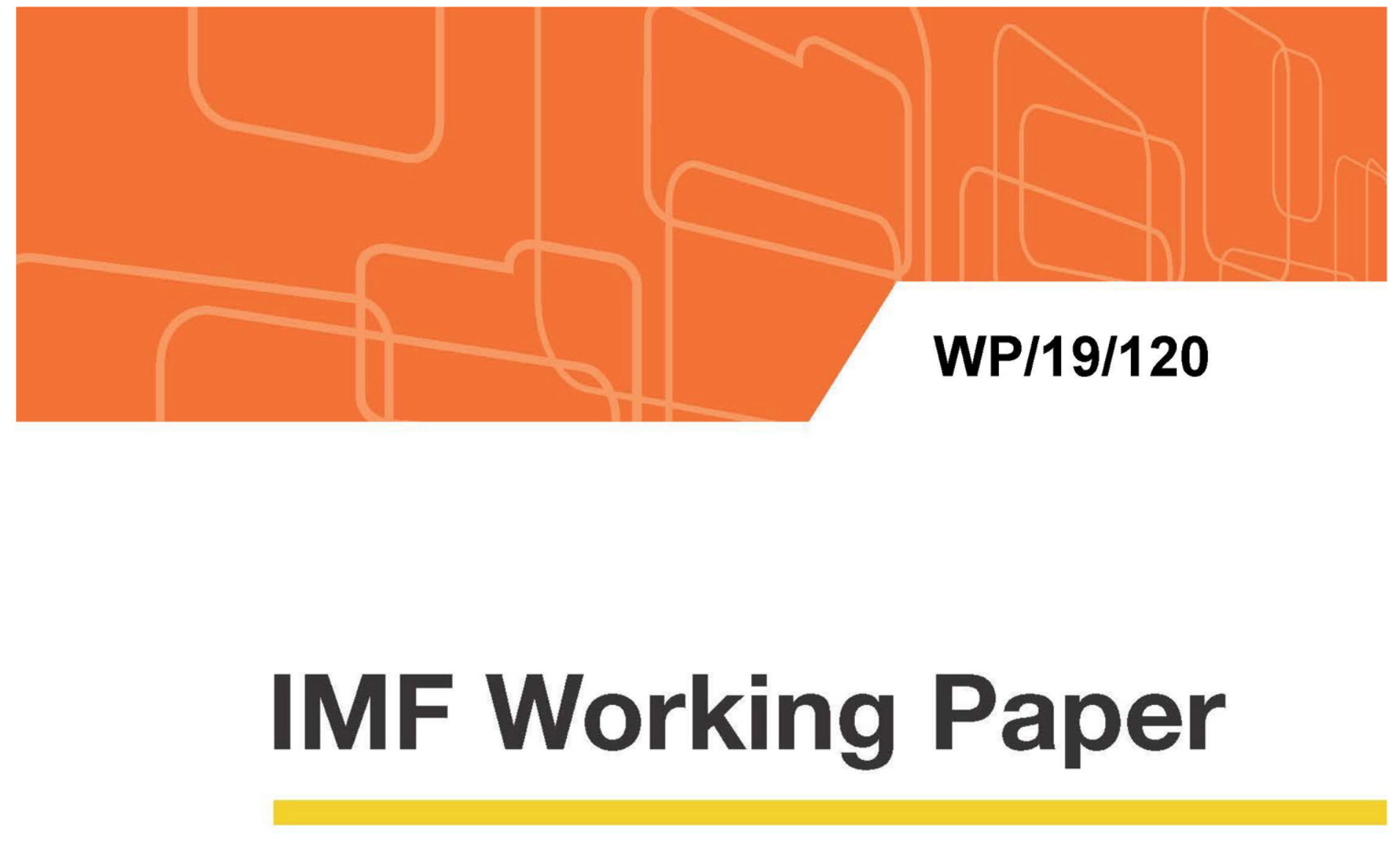

\title{
U.S. Investment Since the Tax Cuts and Jobs Act of 2017
}

by Emanuel Kopp, Daniel Leigh, Susanna Mursula, and Suchanan Tambunlertchai

IMF Working Papers describe research in progress by the author(s) and are published to elicit comments and to encourage debate. The views expressed in IMF Working Papers are those of the author(s) and do not necessarily represent the views of the IMF, its Executive Board, or IMF management. 


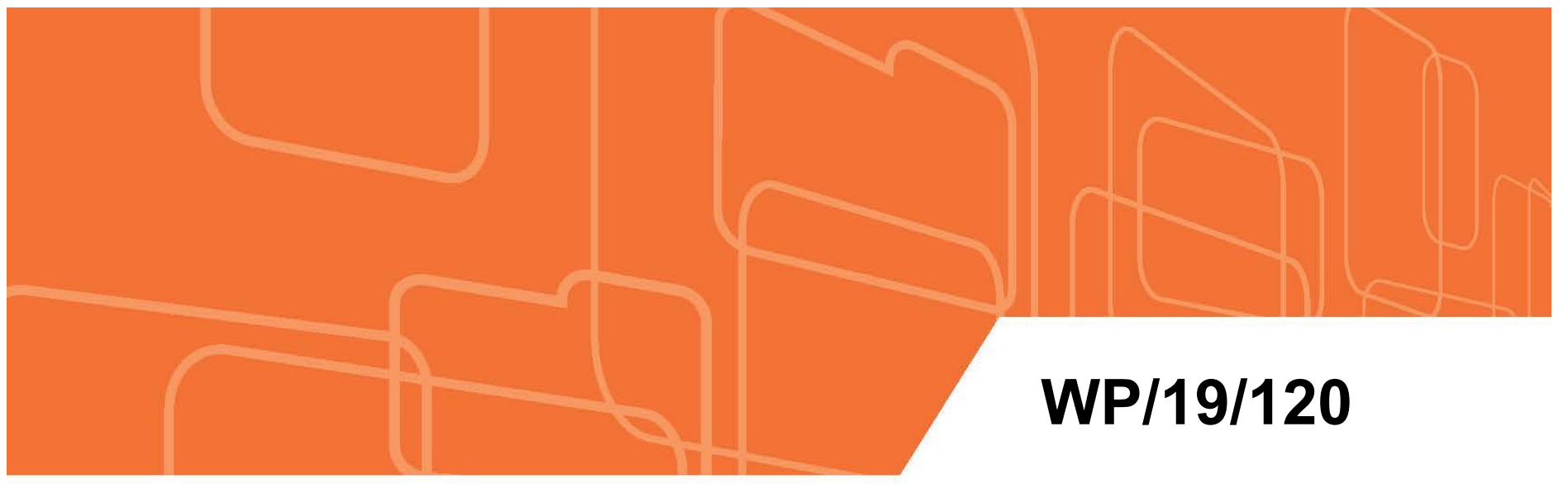

\section{IMF Working Paper}

\section{U.S. Investment Since the Tax Cuts and Jobs Act of 2017}

by Emanuel Kopp, Daniel Leigh, Susanna Mursula, and Suchanan Tambunlertchai

IMF Working Papers describe research in progress by the author(s) and are published to elicit comments and to encourage debate.

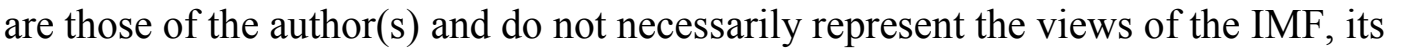

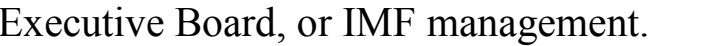

I N T E R N A T I O N A L M O N E T A R Y F U N D 


\title{
IMF Working Paper
}

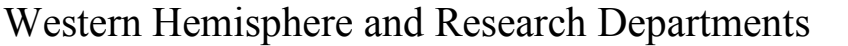

\section{U.S. Investment Since the Tax Cuts and Jobs Act of 2017 \\ Prepared by Emanuel Kopp, Daniel Leigh, Susanna Mursula, and Suchanan Tambunlertchai ${ }^{1}$}

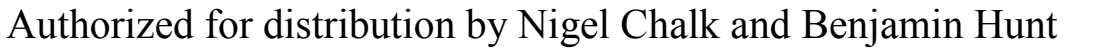

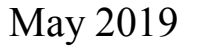

IMF Working Papers describe research in progress by the author(s) and are published to

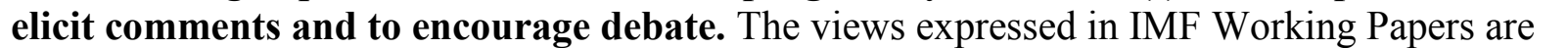

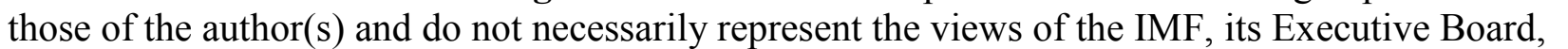

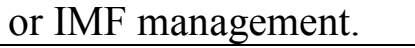

\begin{abstract}

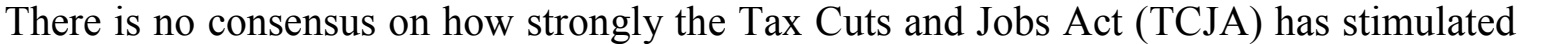

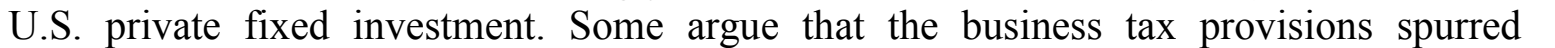

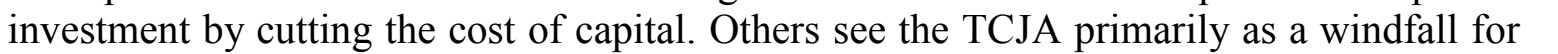

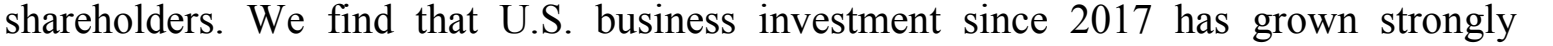

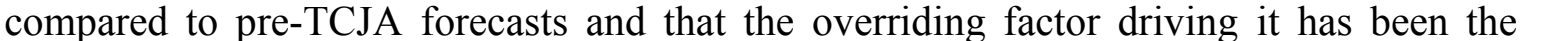

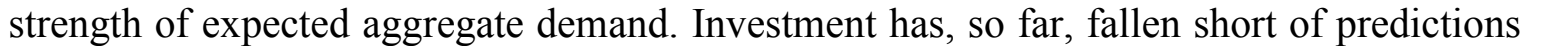

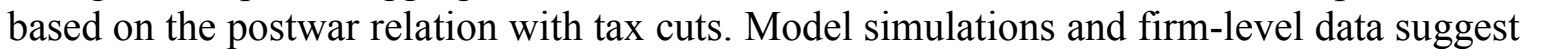

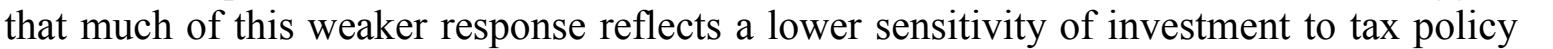

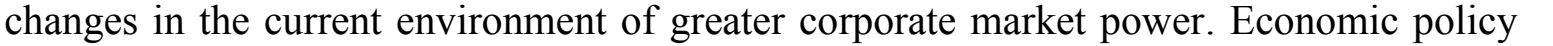

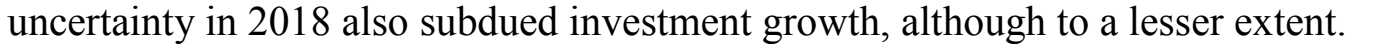

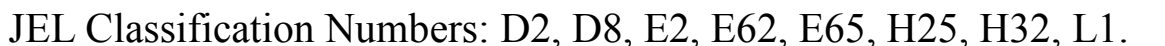

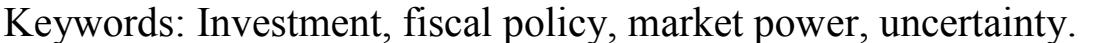

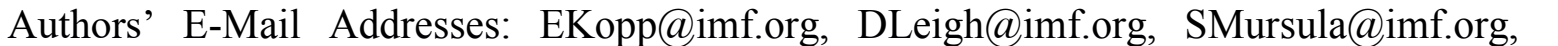

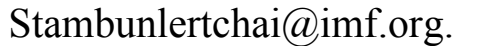

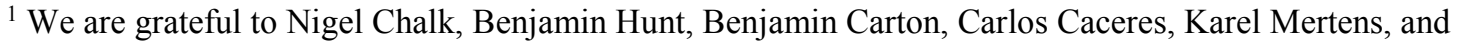

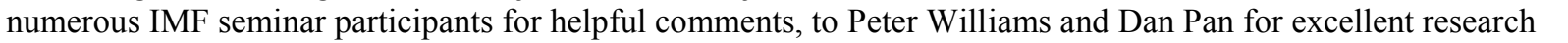

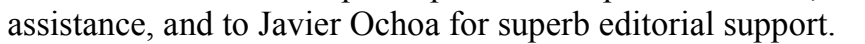

CInternational Monetary Fund. Not for Redistribution 


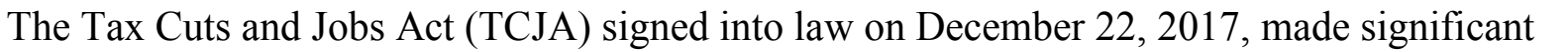

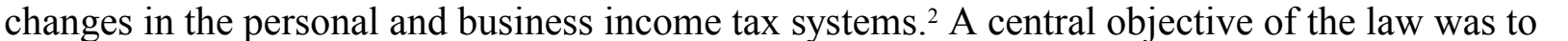

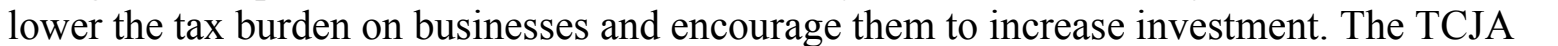

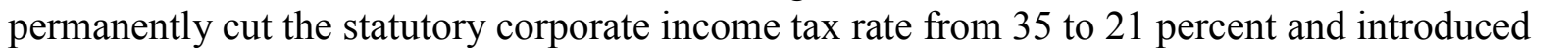

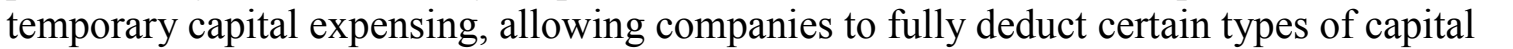

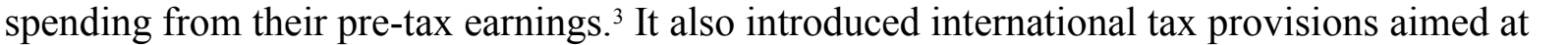

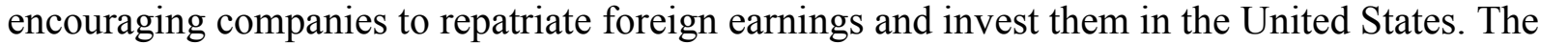

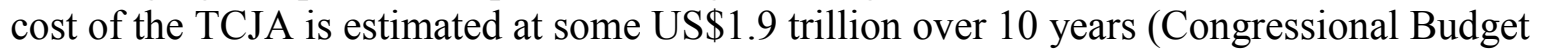

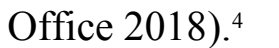

$\square$

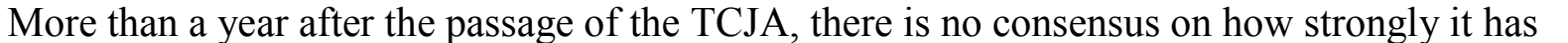

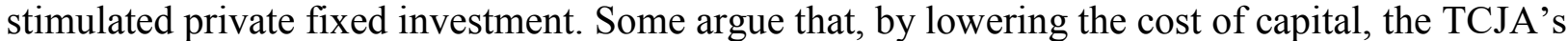

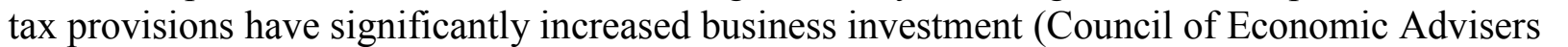

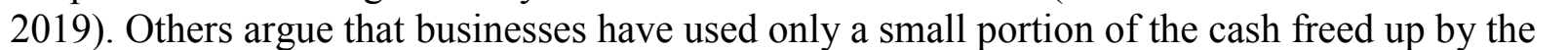

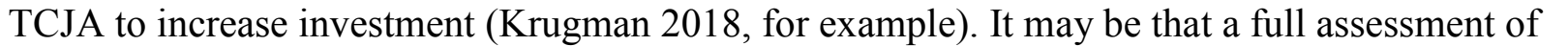

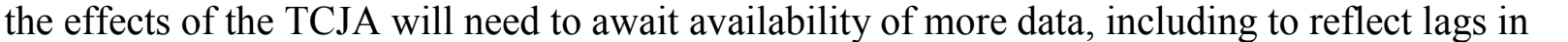

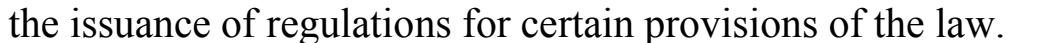

$\square$

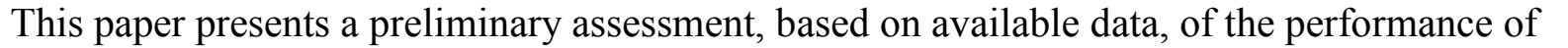

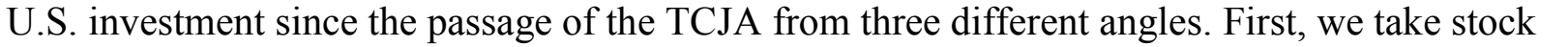

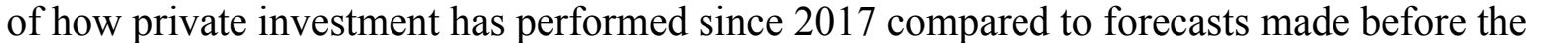

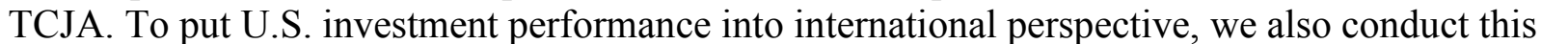

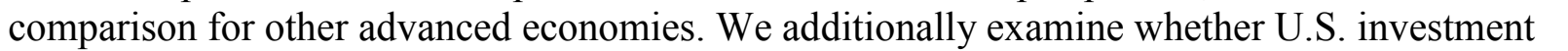

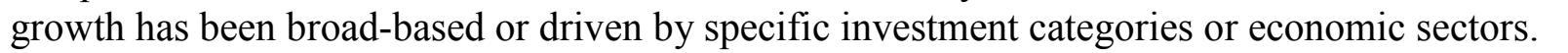

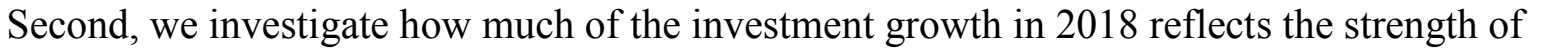

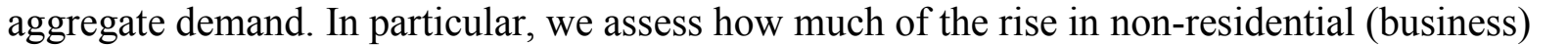

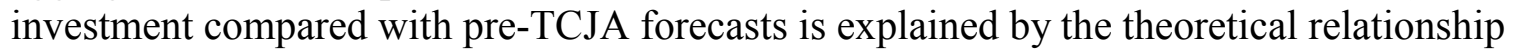

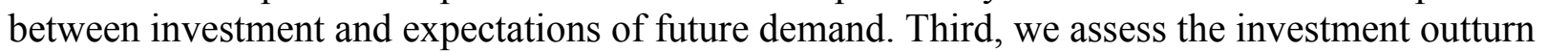

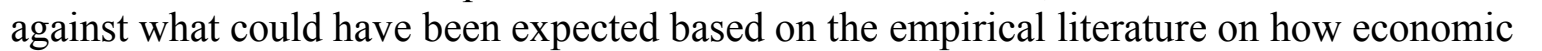

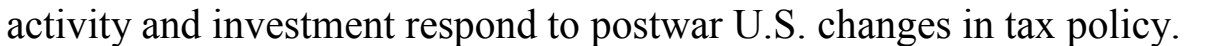

$\square$

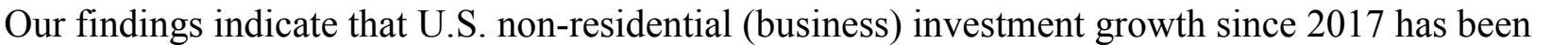

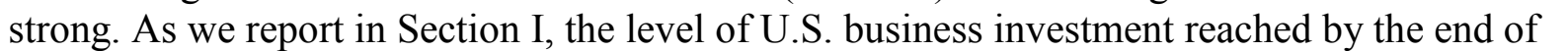

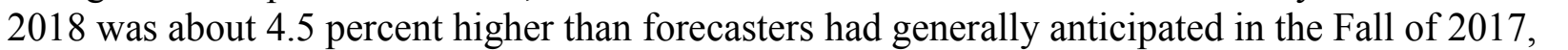

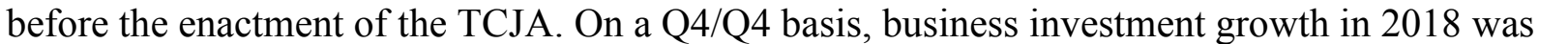

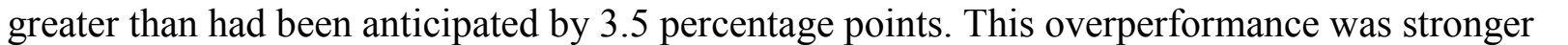

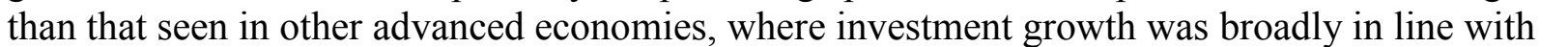

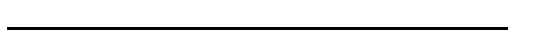

The law's formal title is "HR1: An Act to provide for reconciliation pursuant to titles II and V of the concurrent

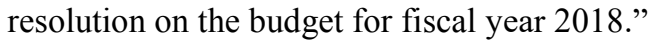

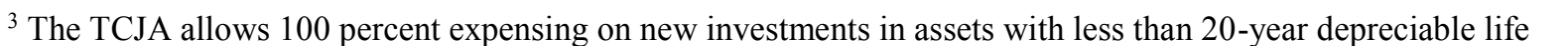

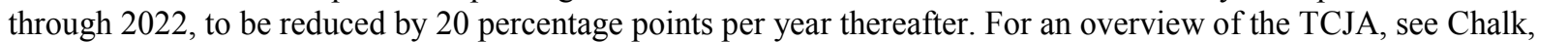

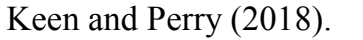

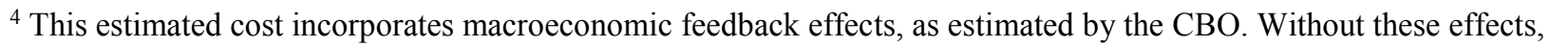

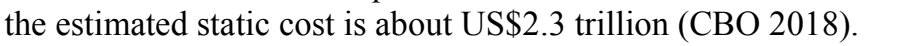




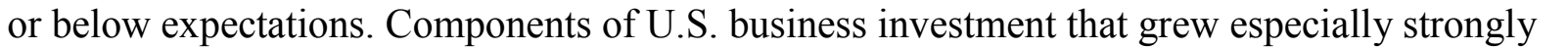

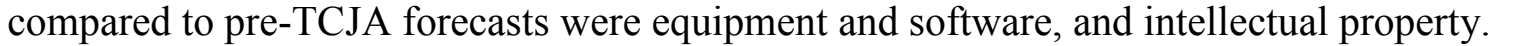
$\square$

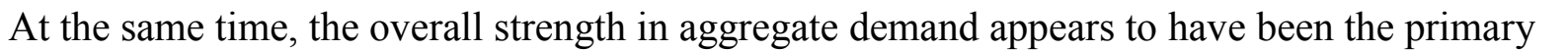

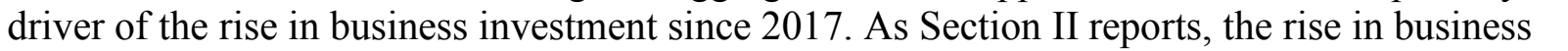

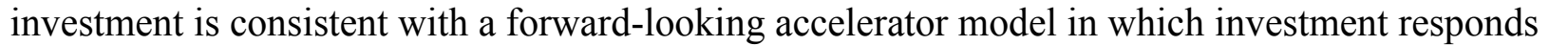

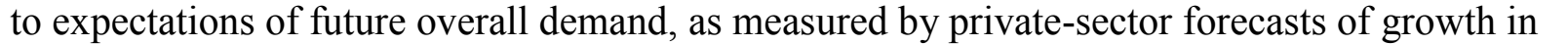

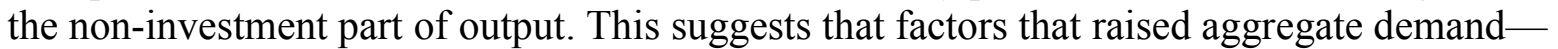
ए एव

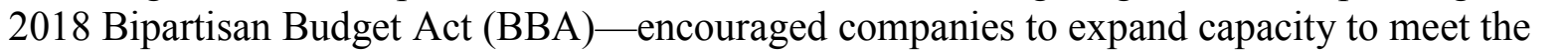

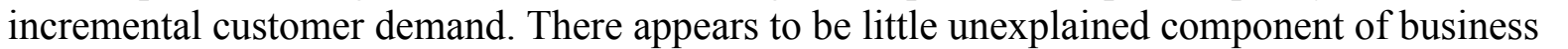
एம

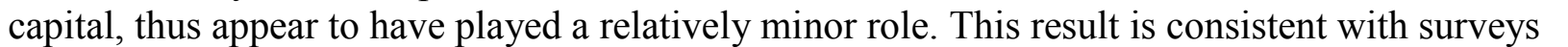

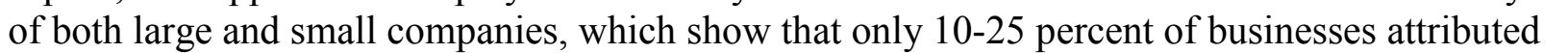

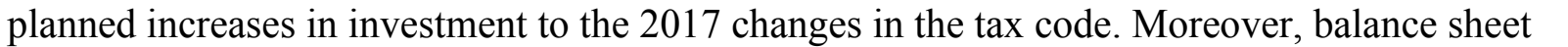

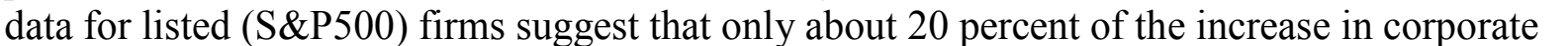

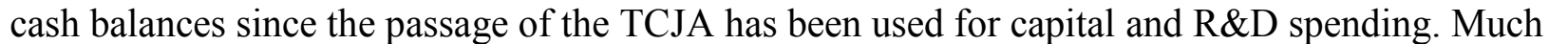

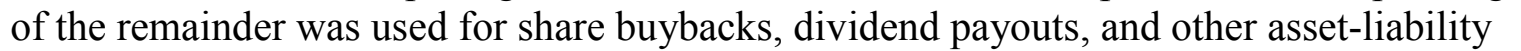

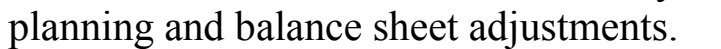

$\square$

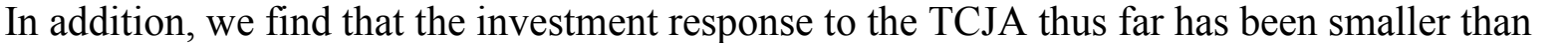

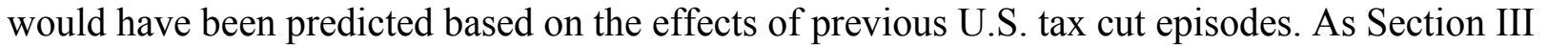

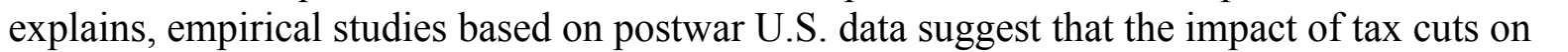

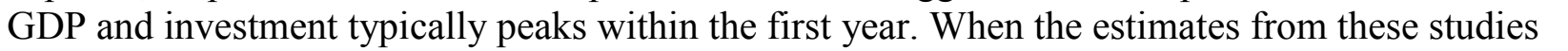

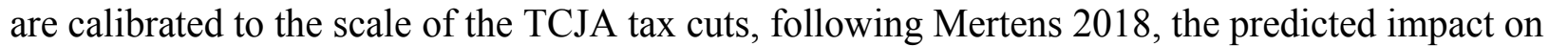
ப

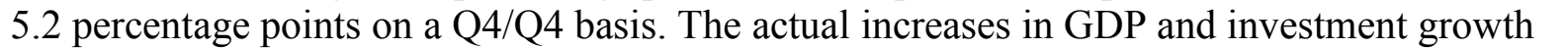

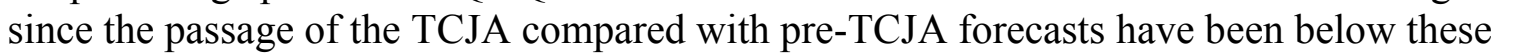

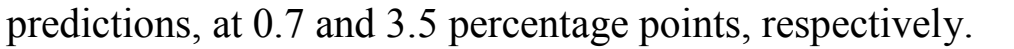

$\square$

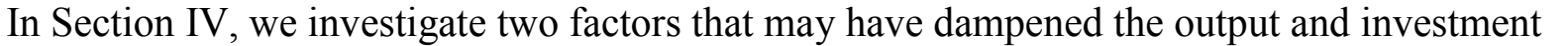

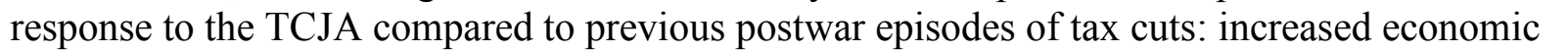

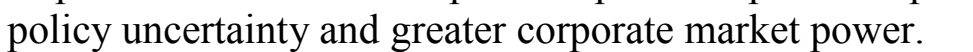

$\square$

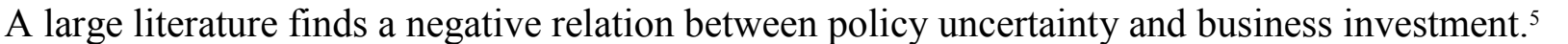

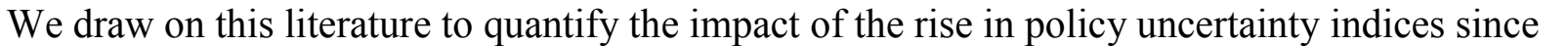

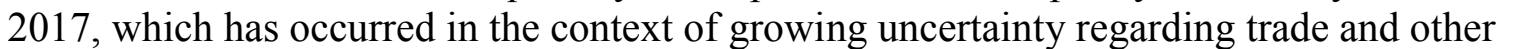

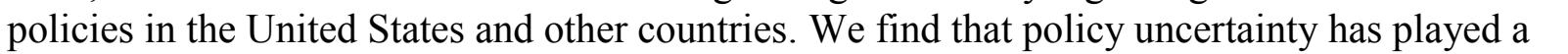

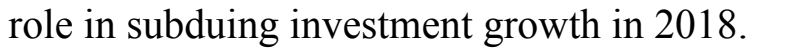

$\square$

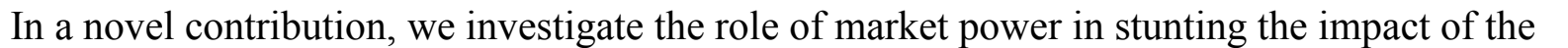

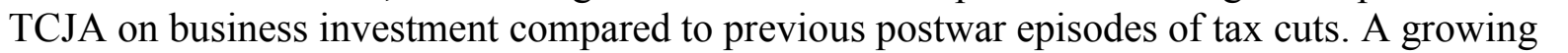

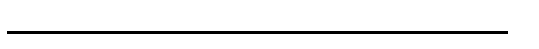

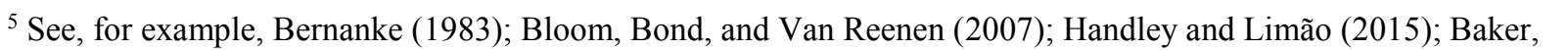

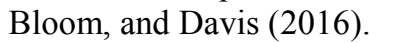




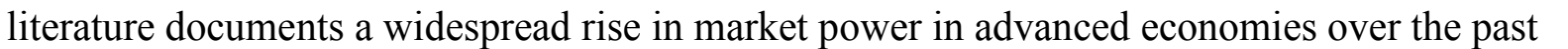

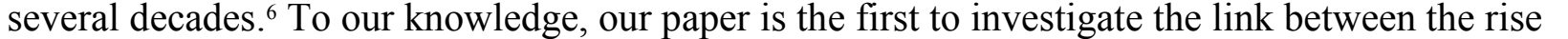

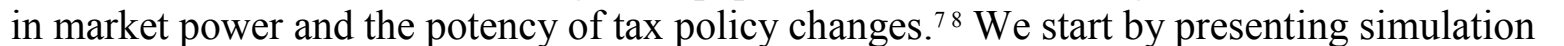

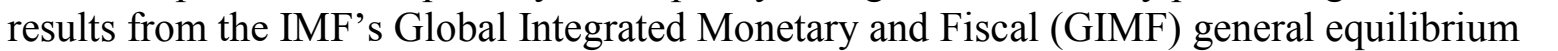

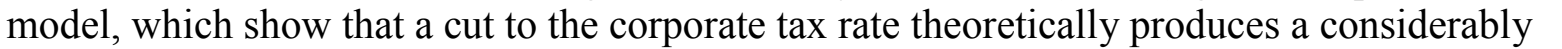

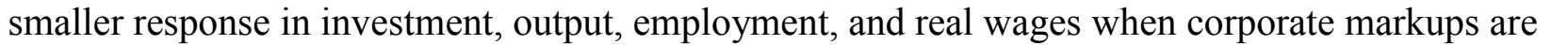

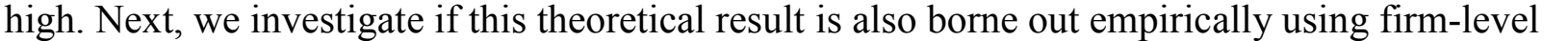

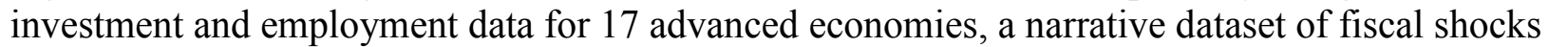

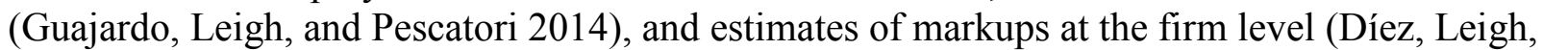

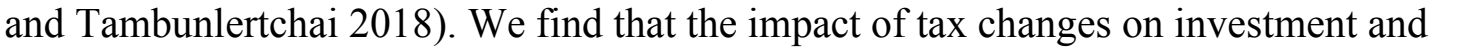

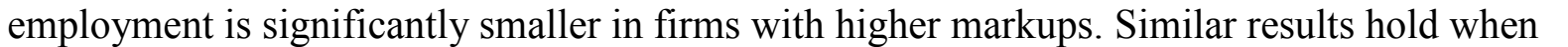
ए।

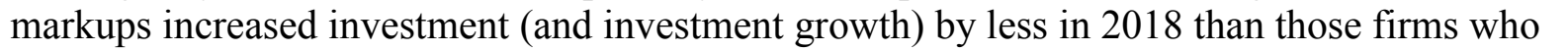

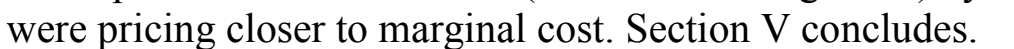

$\square$

\section{How Has U.S. Private Investment Performed Since 2017?}

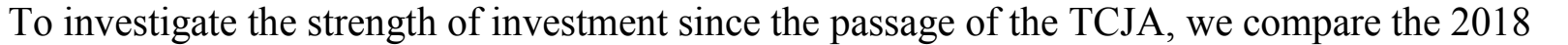

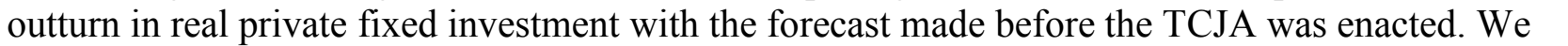

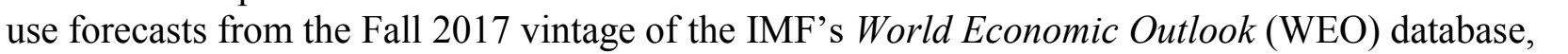

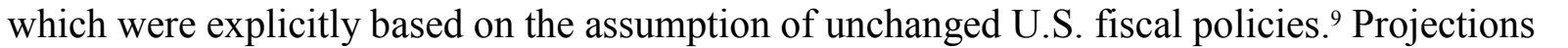

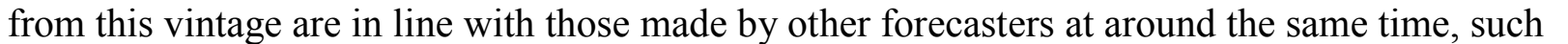

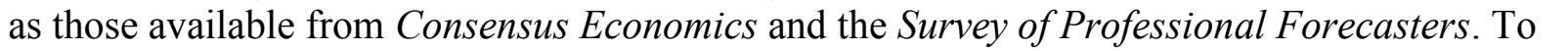

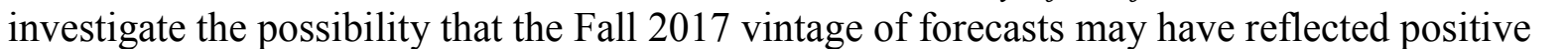

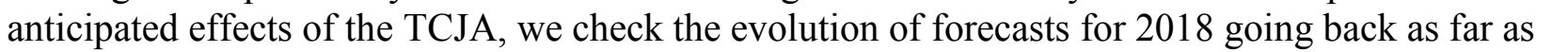

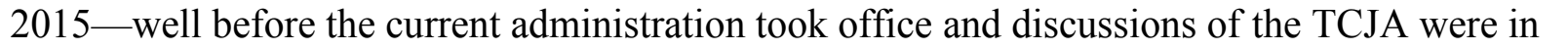

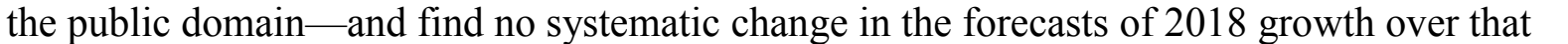

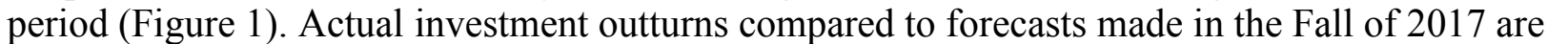
पा

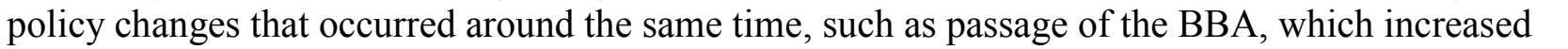

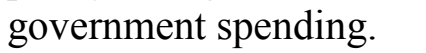

$\square$

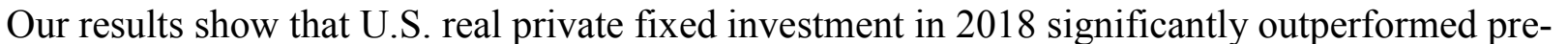

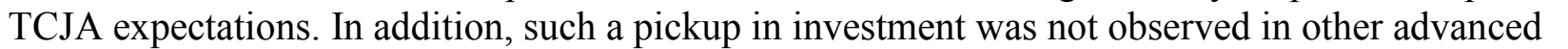
m m

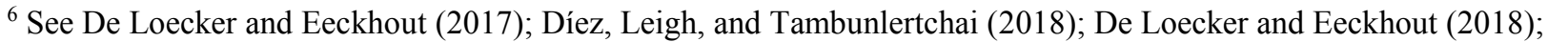

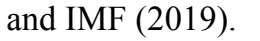

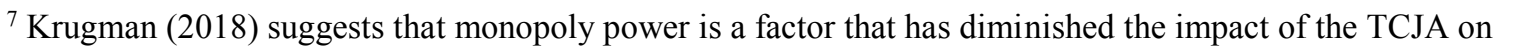
एणाणापाण

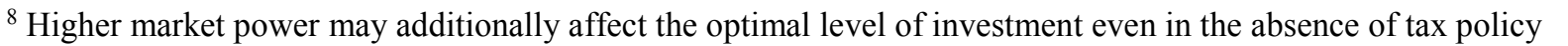

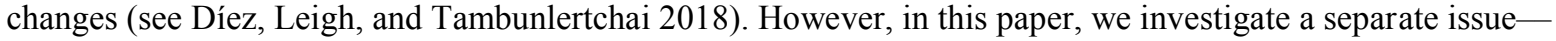

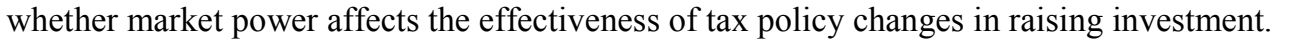

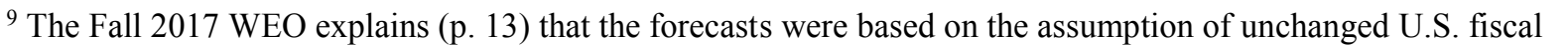

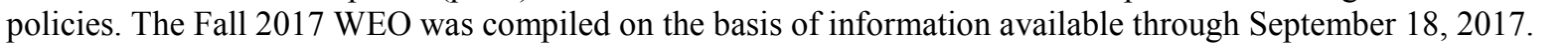




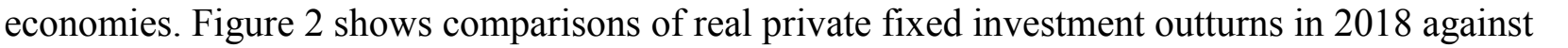

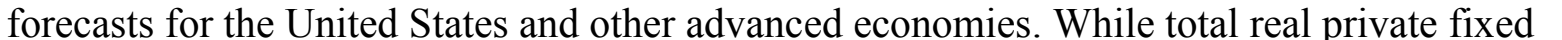

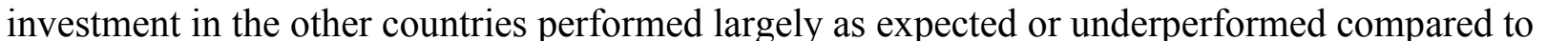

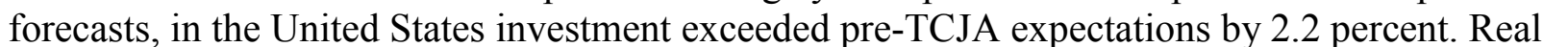

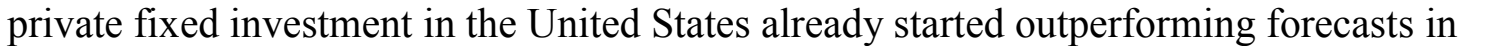
$\square \square \square \square \square$

$\square$

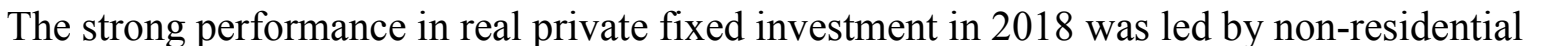

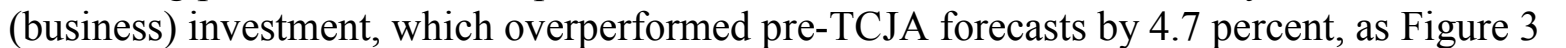

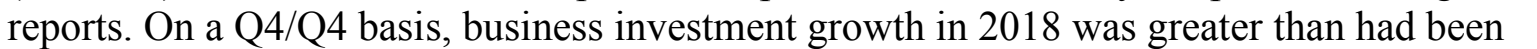

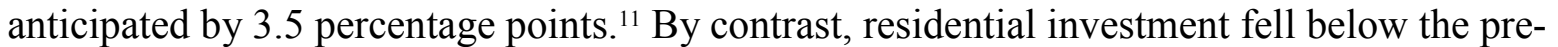

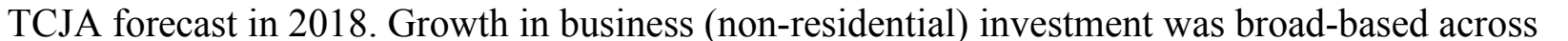

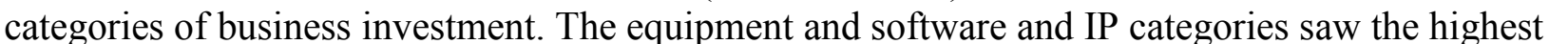

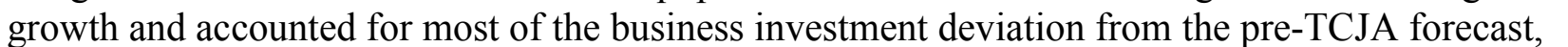

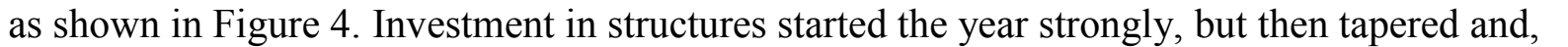

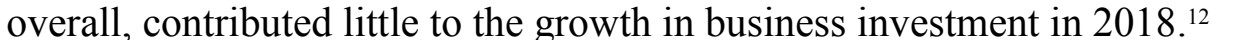

$\square$

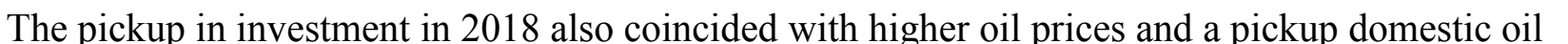

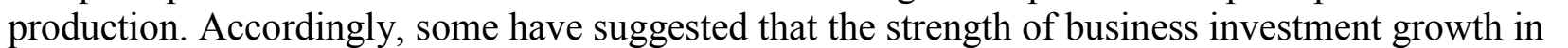

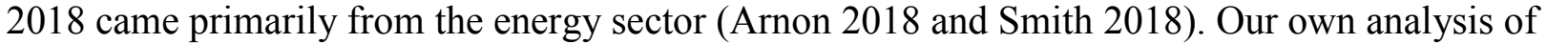

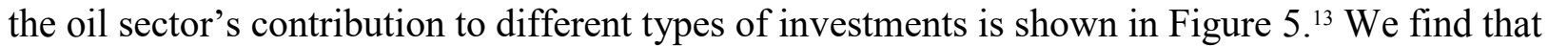

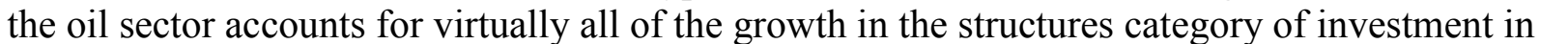

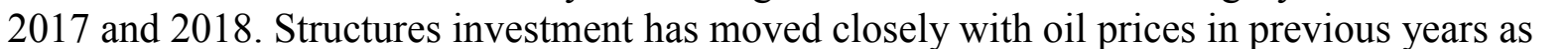

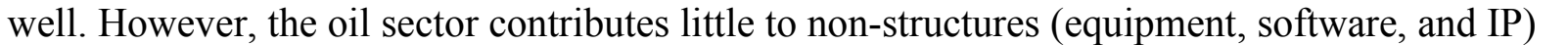

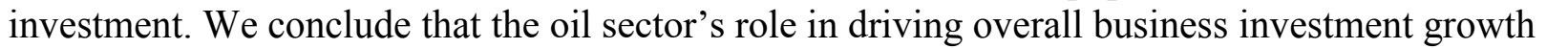

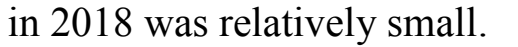

$\square$

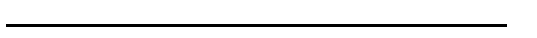

प्र एण

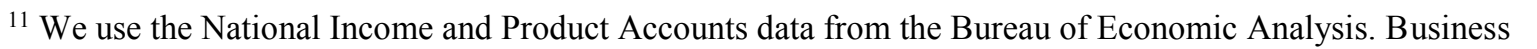
ए

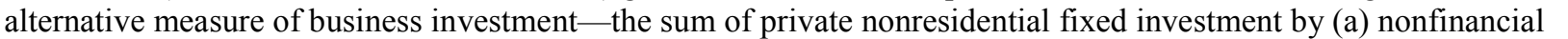

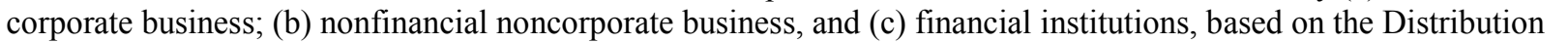

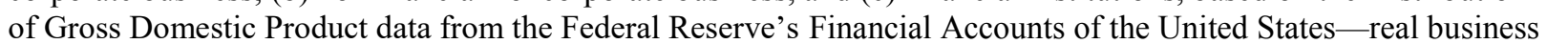

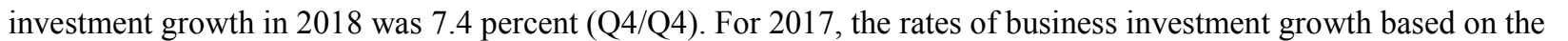

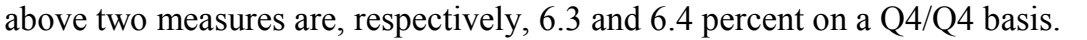

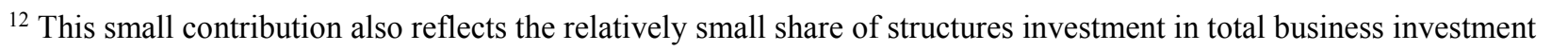

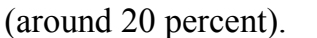

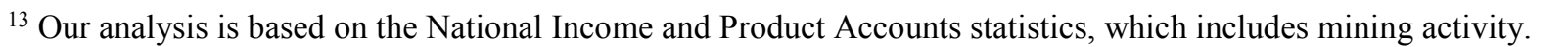




\section{How Much OF The Higher InVestment Reflects the StRength OF AggRegate DEMAND?}

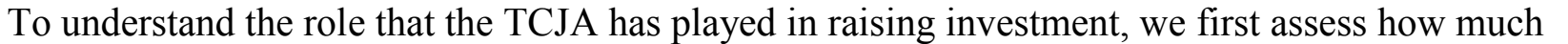

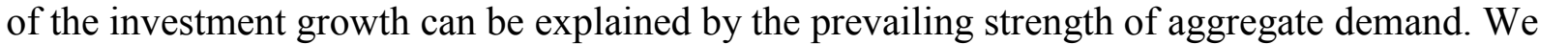

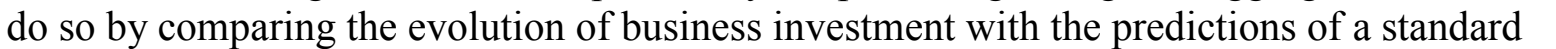

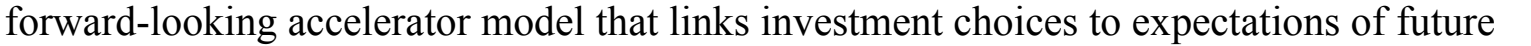

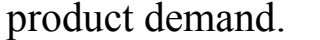

$\square$

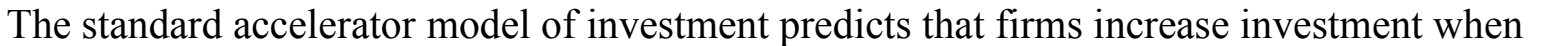

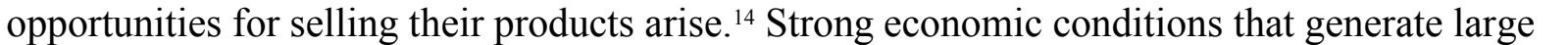

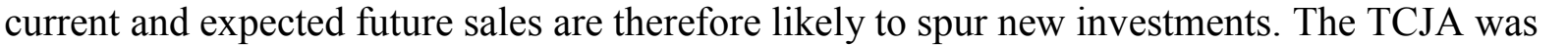

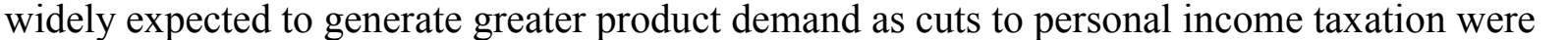

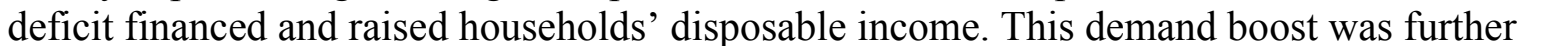

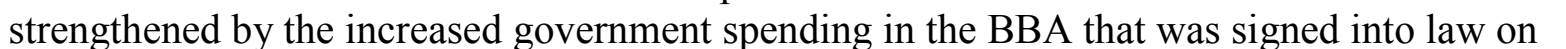

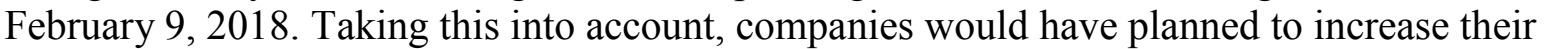
ए

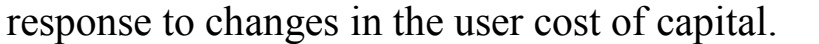

$\square$

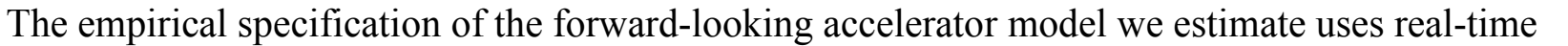

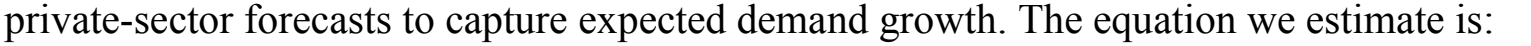

$\square$

$\square \quad I_{t}=\alpha+\beta(L) E_{t} \Delta Y_{t+h}+\delta K_{t-1}+\epsilon_{t} \square$

$\square$

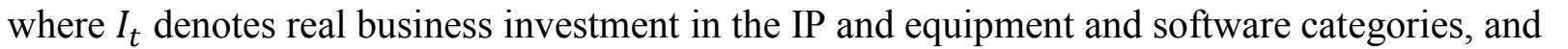

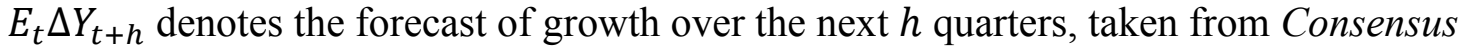

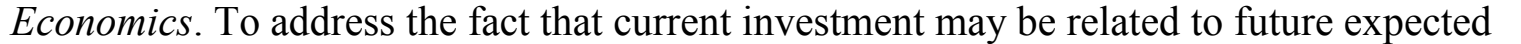

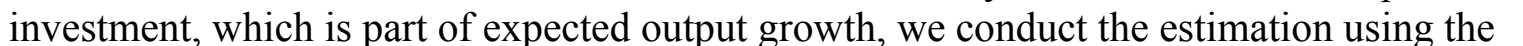

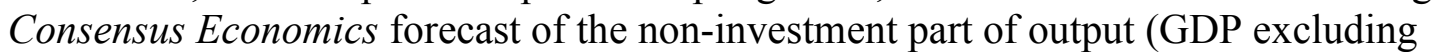

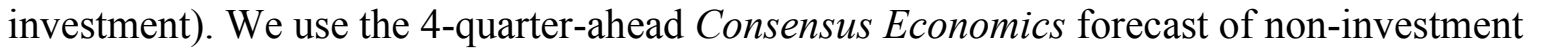

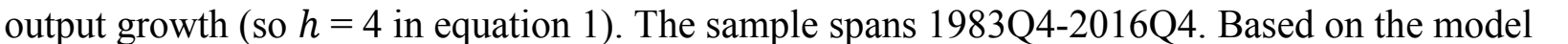

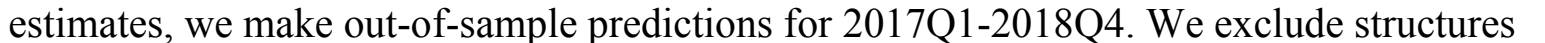

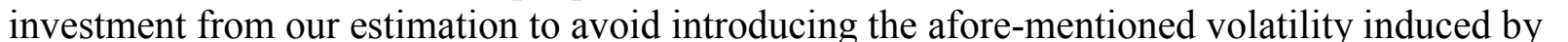

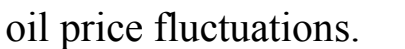

$\square$

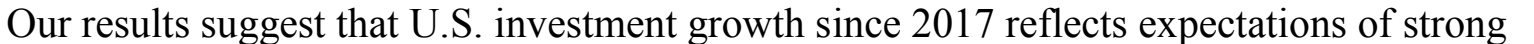

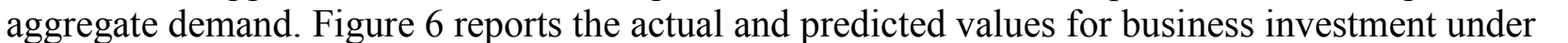

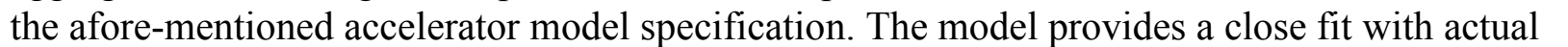
ए

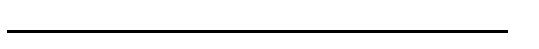

ए

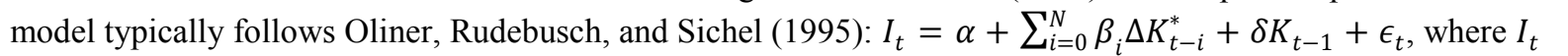

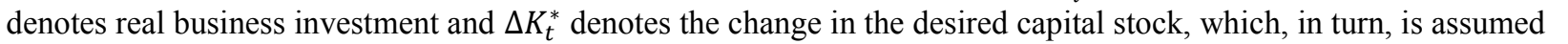

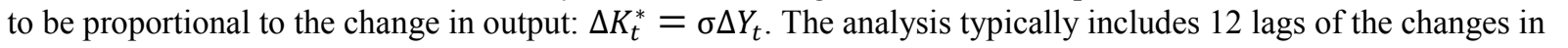

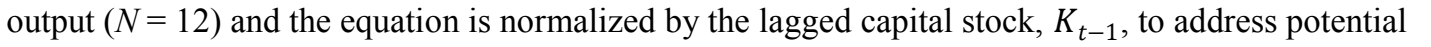

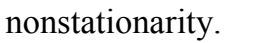




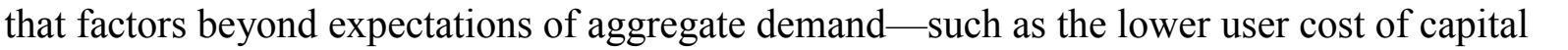

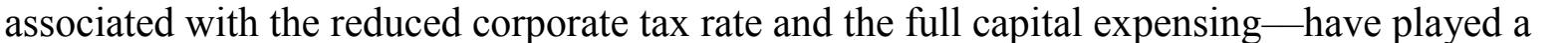

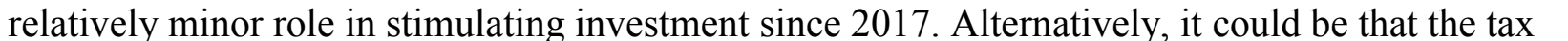

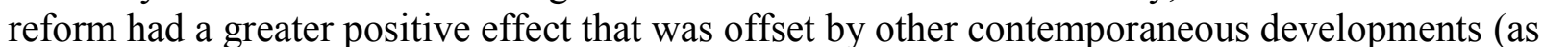

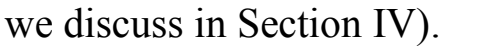

$\square$

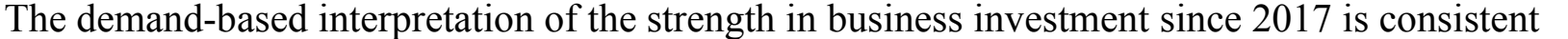

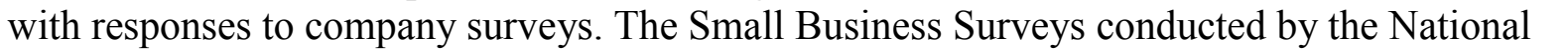

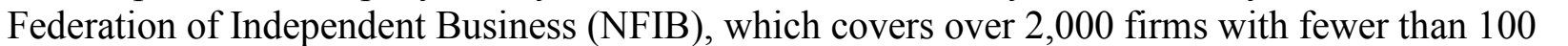

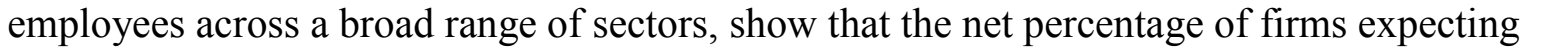

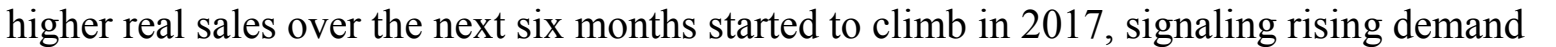

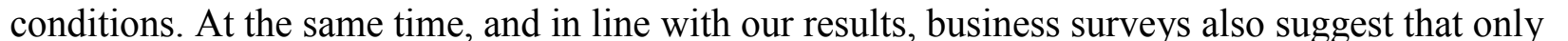

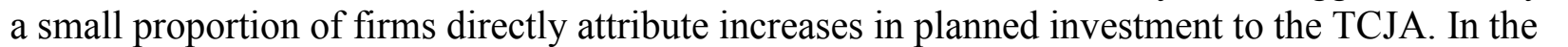

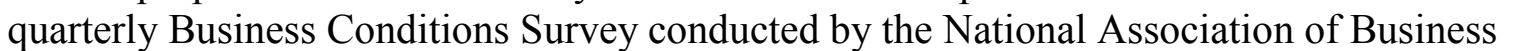

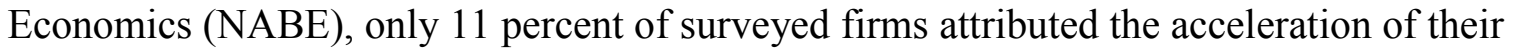

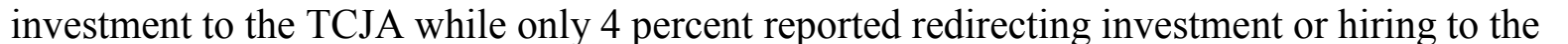

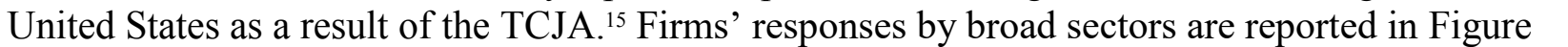

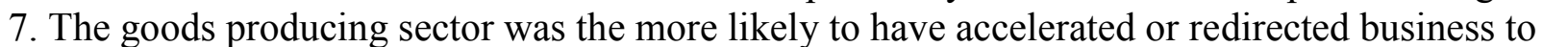

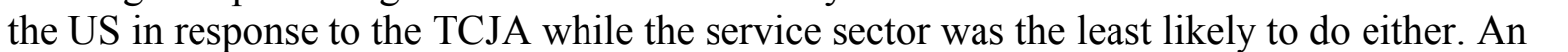

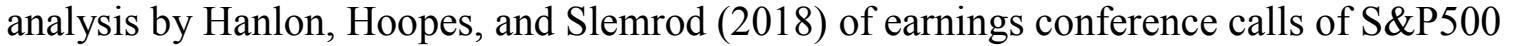

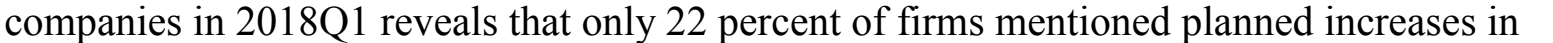

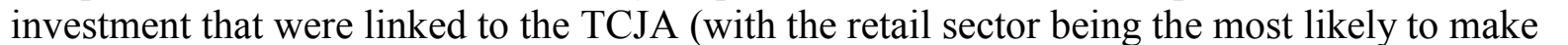

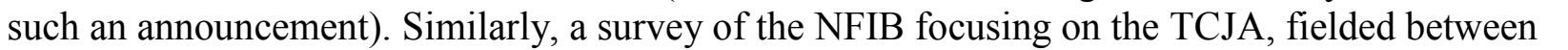

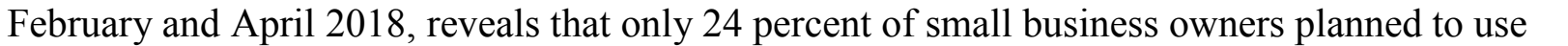

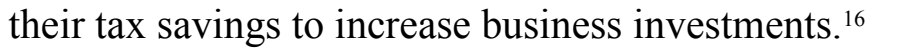

$\square$

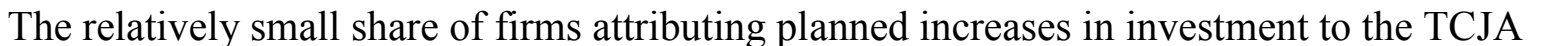

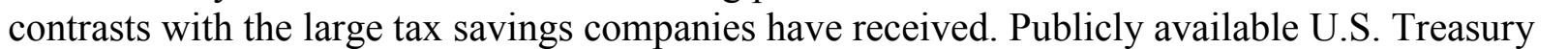
पाm

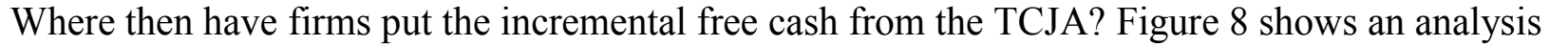

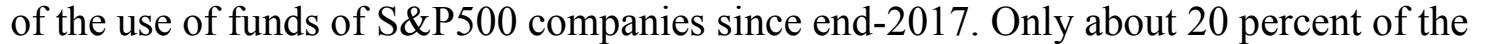

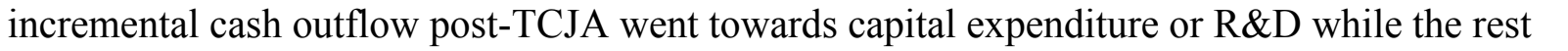

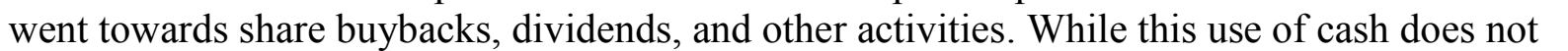

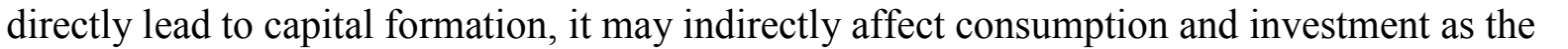

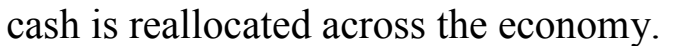

$\square$

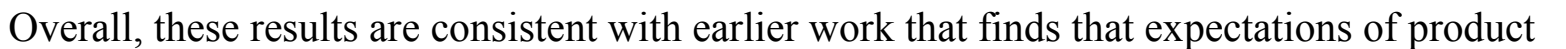

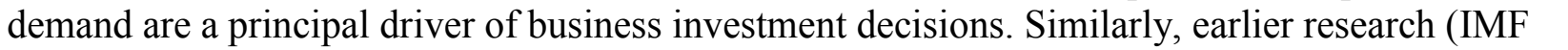

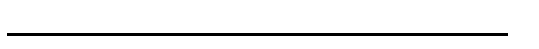

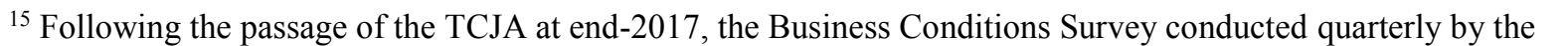

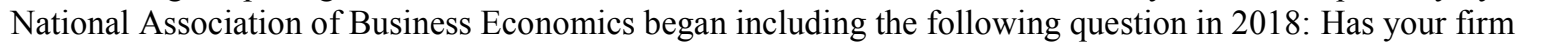

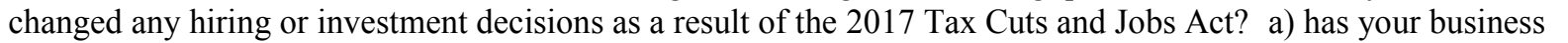

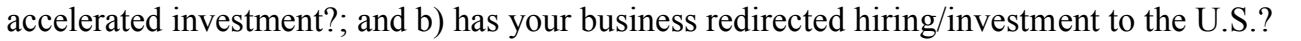

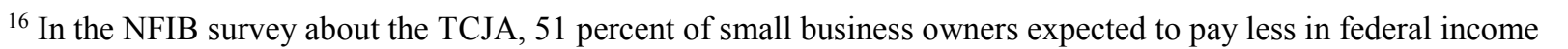
ए ए 


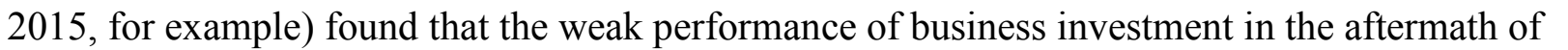
ए

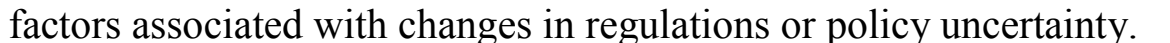

$\square$

\section{How Has Investment Performed Compared With the Historical Relation BETWEEN TAX CUTS AND INVESTMENT?}

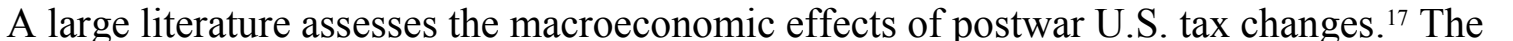

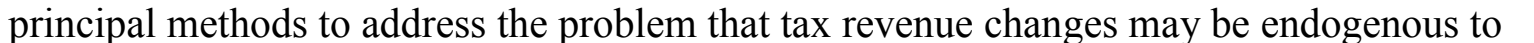

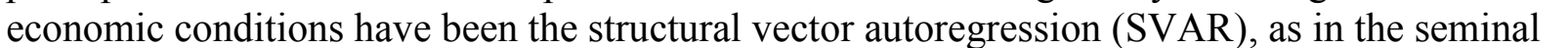

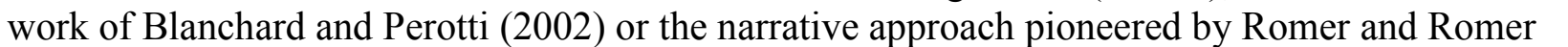

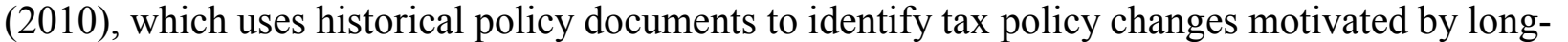

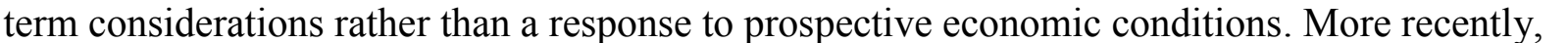

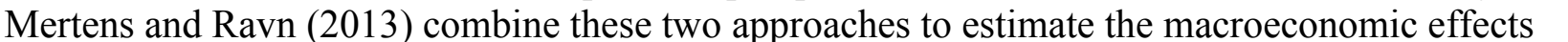

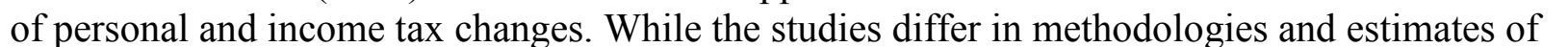
ए

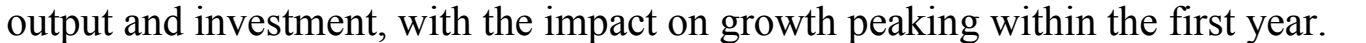

$\square$

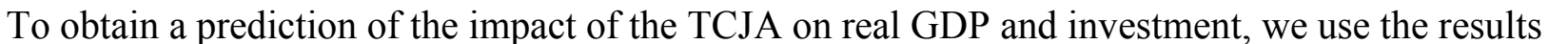

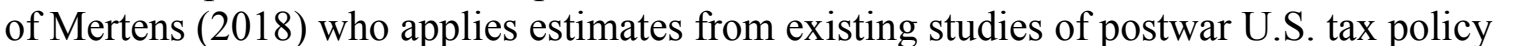

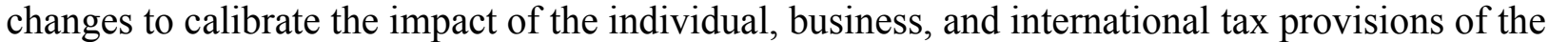

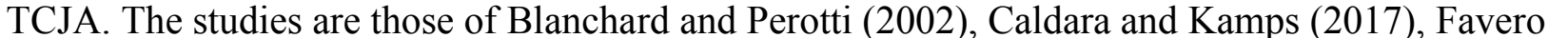

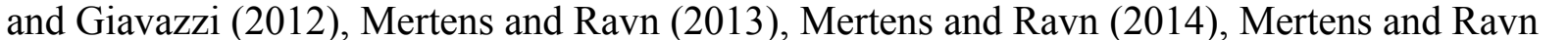

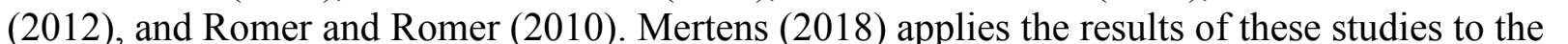

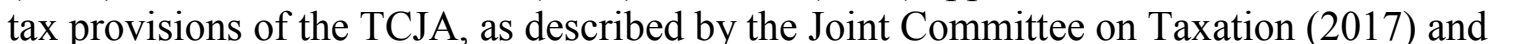

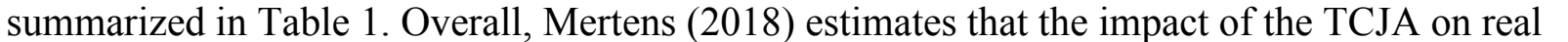

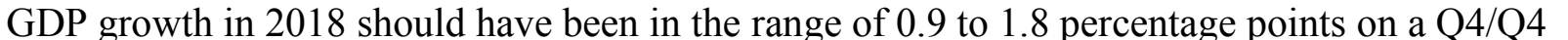

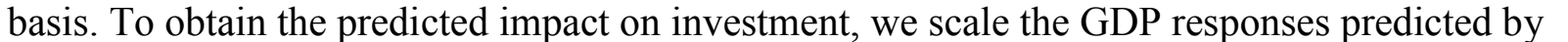

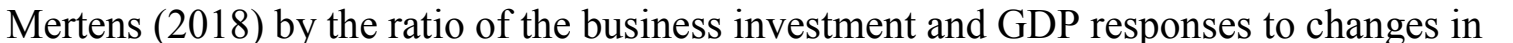

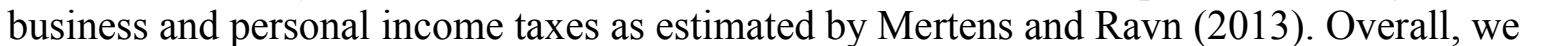

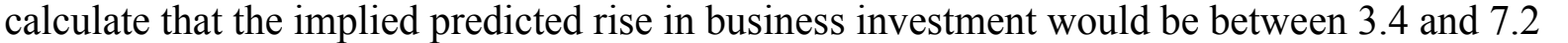

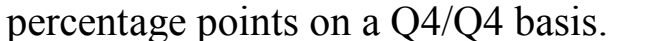

$\square$

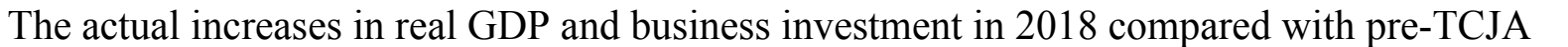

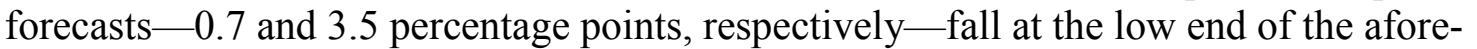

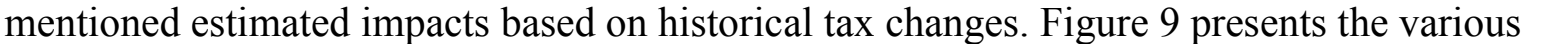

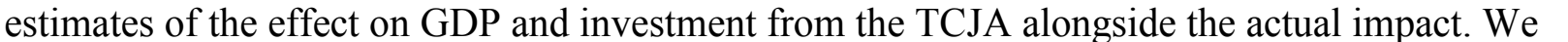

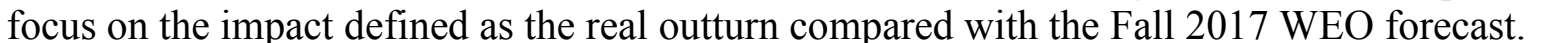

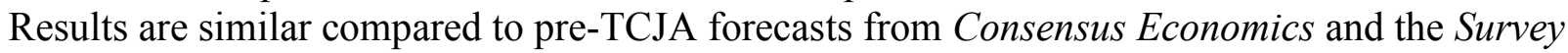

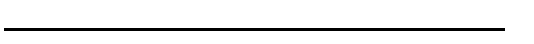

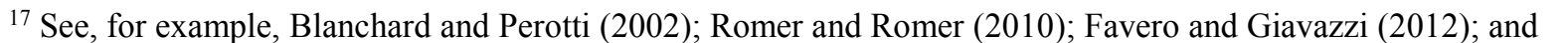

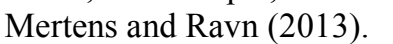




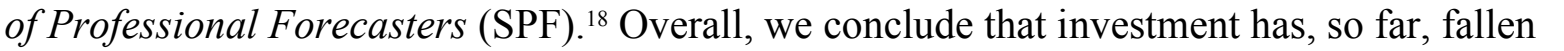

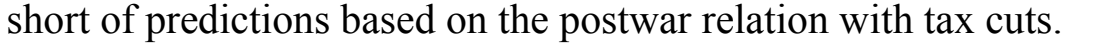

$\square$

\section{What May HaVe Held BaCK InVestment?}

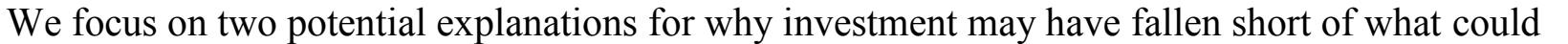

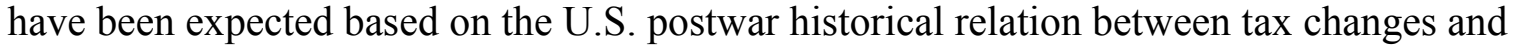
ए

$\square$

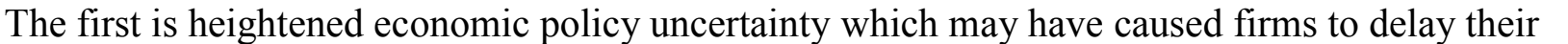

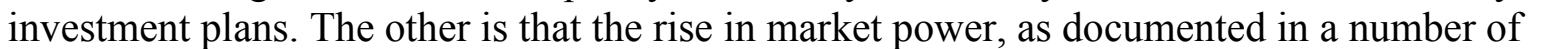

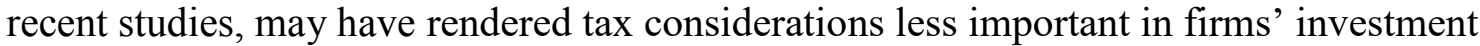

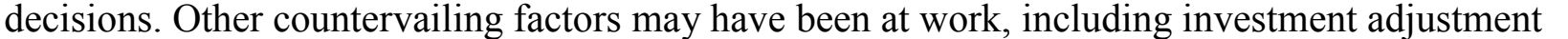

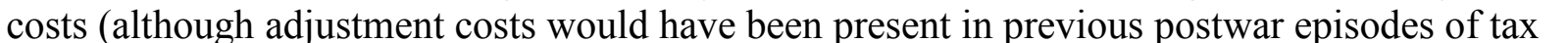

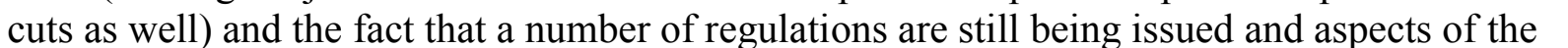

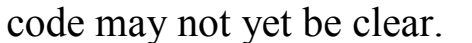
$\square$

\section{A. Policy Uncertainty}

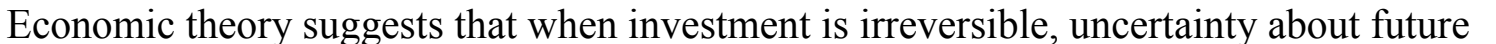

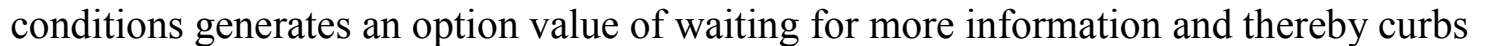
ए

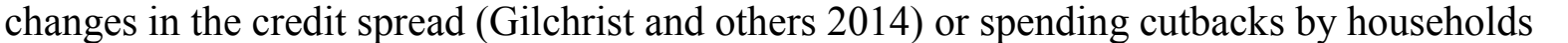

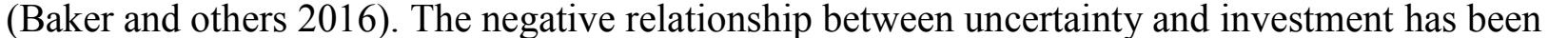

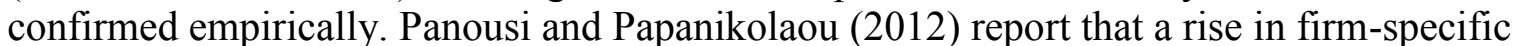

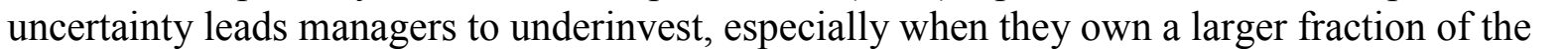

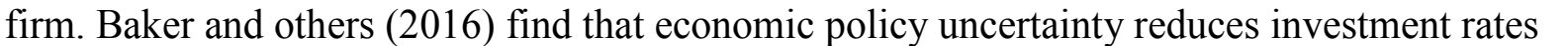

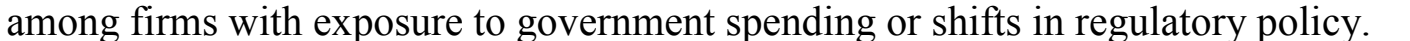

$\square$

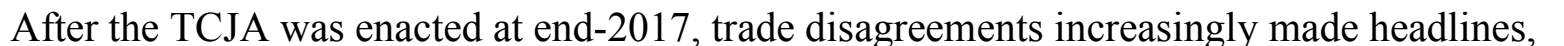

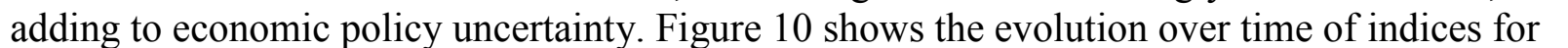

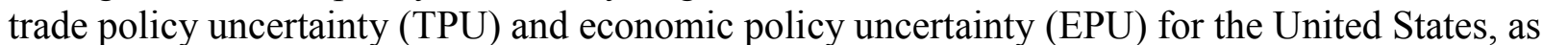

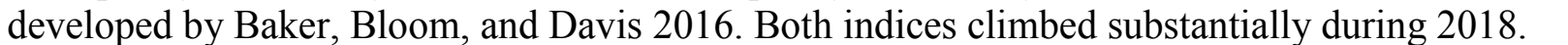
$\square$

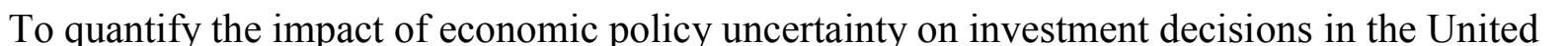

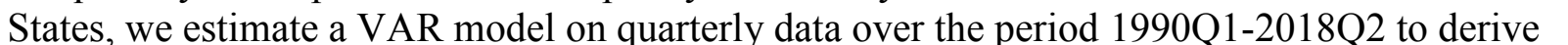
ए

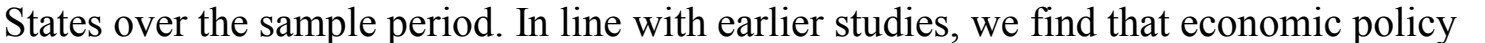

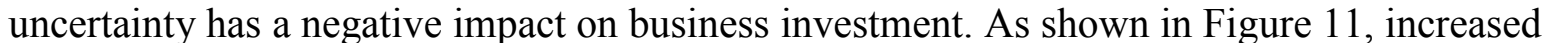

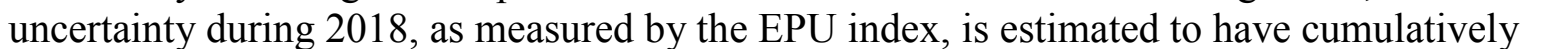

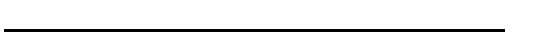

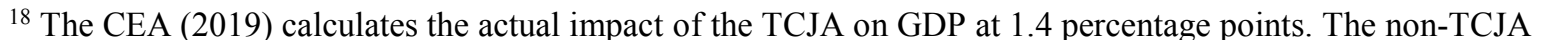

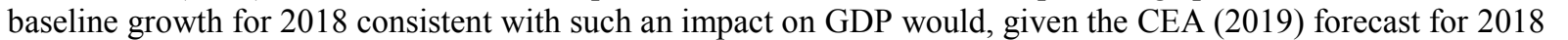

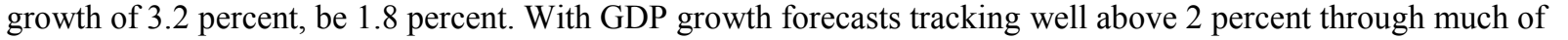

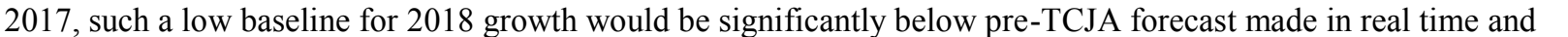

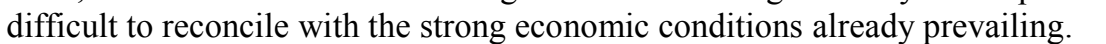




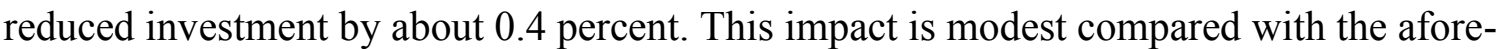

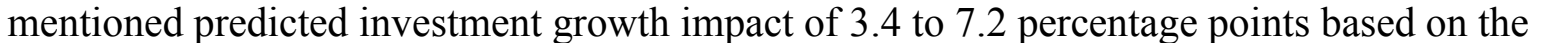

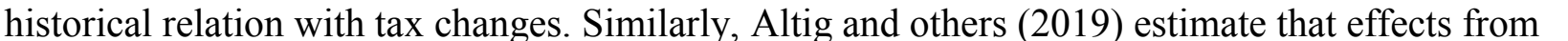

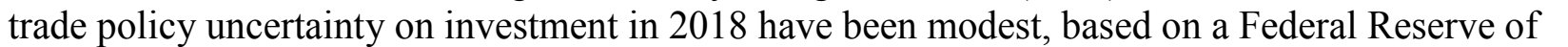

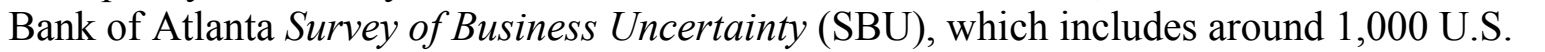

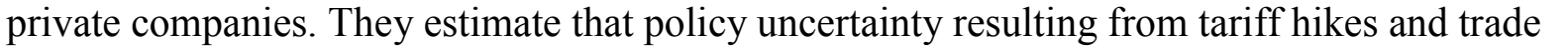

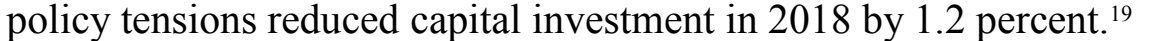

$\square$

\section{B. The Role of Market Power}

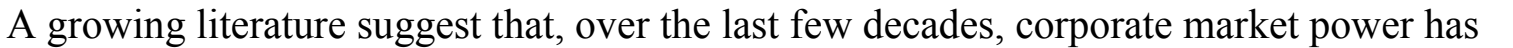
ए

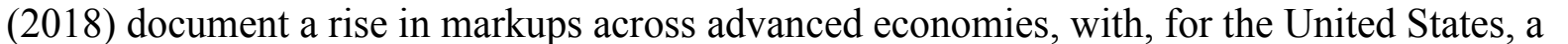
पाm

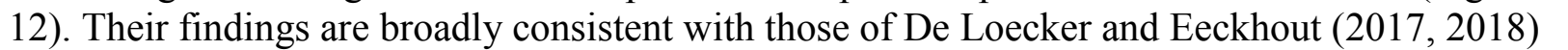

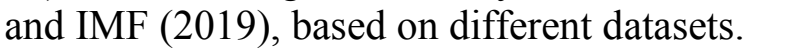

$\square$

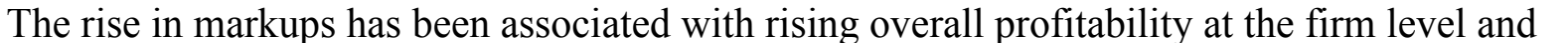

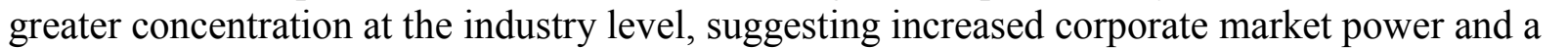

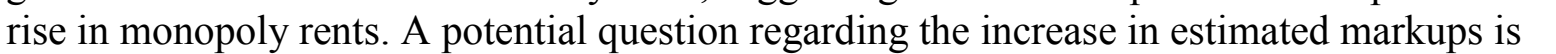

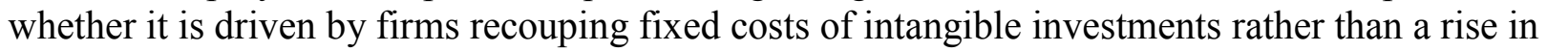

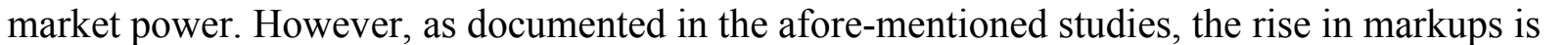

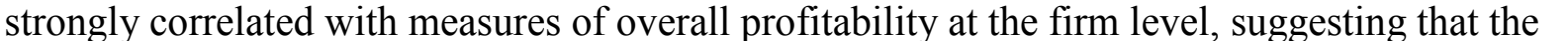

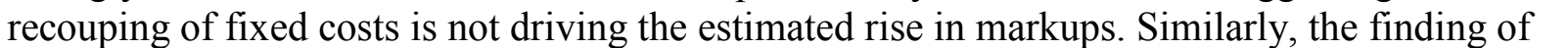

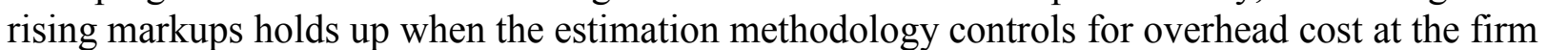

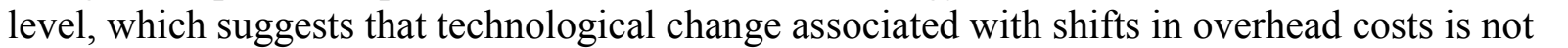

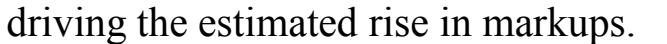

$\square$

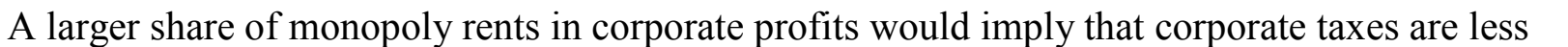

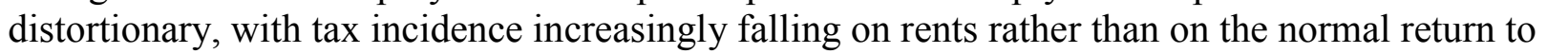

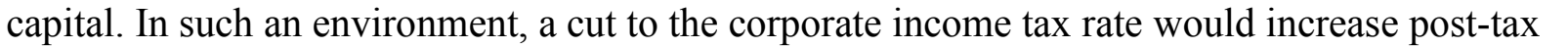

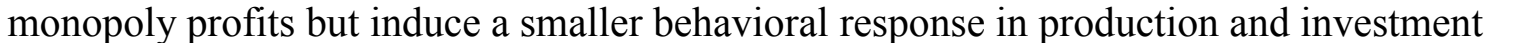

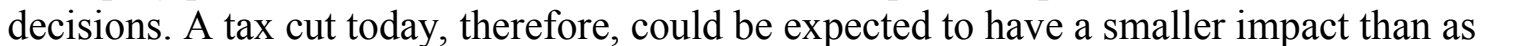

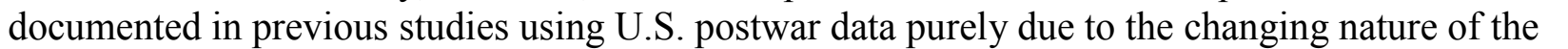
ए ए।

$\square$

\section{Role of Market Power: Model Simulations}

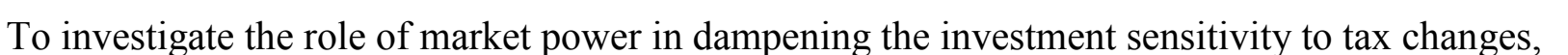

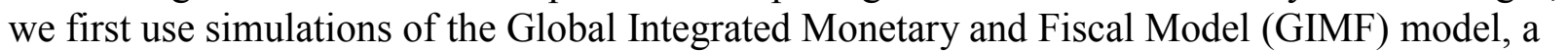

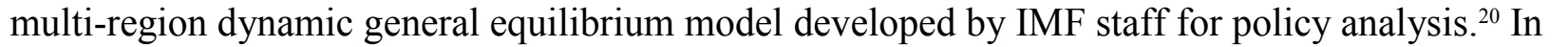
(1)

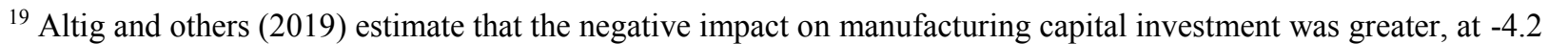

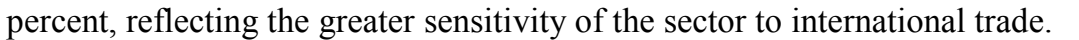

"See Kumhof, Laxton, Mursula, and Muir (2010) for an overview of the GIMF model’s structure. $\square$ 


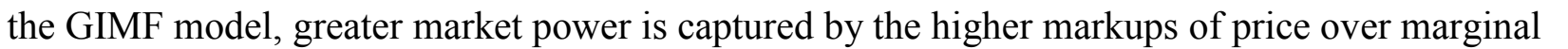

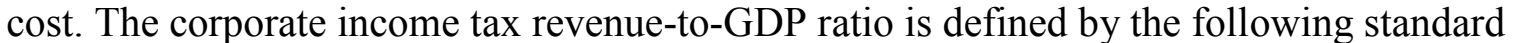

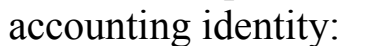

$\square$

$\square \quad \frac{T^{C I T}}{Y}=\tau^{C I T}\left[\left(R^{K}-\delta\right) \frac{K}{Y}+\left(1-\frac{1}{\mu}\right)\right] \square$

$\square$

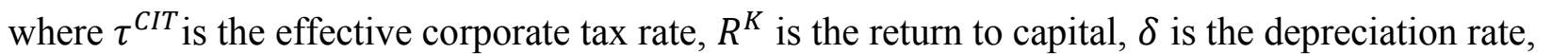

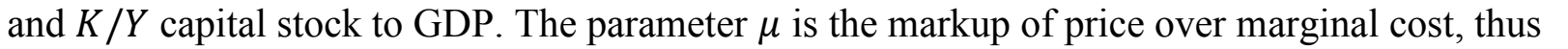

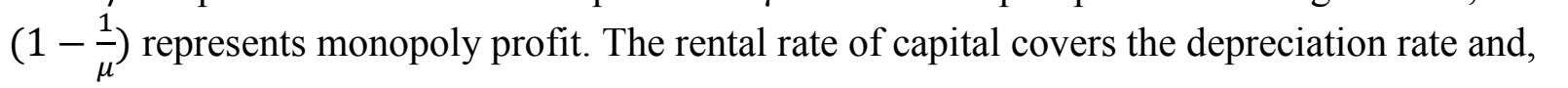

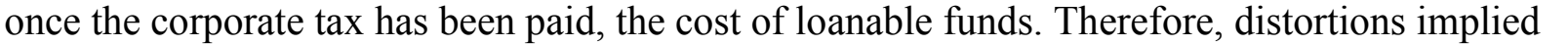

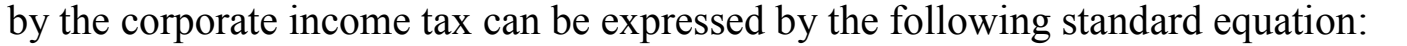

$\square$

$\square \quad R^{K}-\delta=\frac{r}{\left(1-\tau^{C I T}\right)} \square$

$\square$

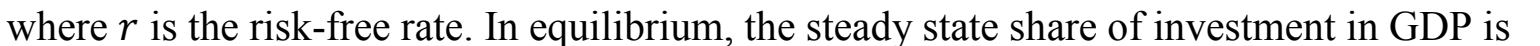

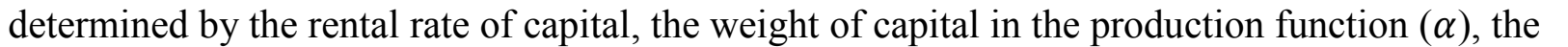

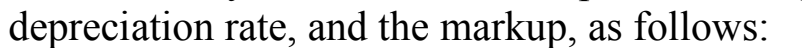

$\square$

$\square \quad \frac{I}{Y}=\frac{\delta \alpha}{\mu R^{K}} \square$

$\square$

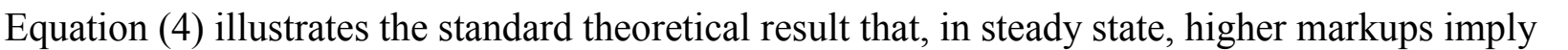

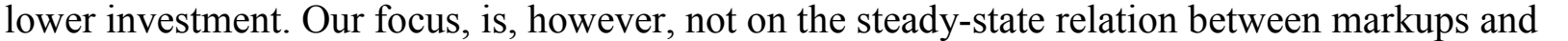
एव

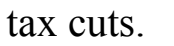

$\square$

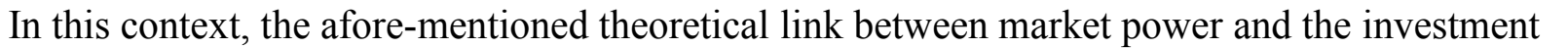

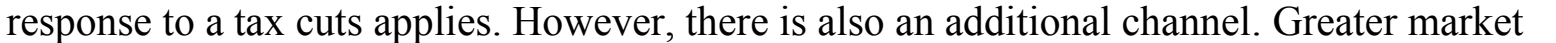

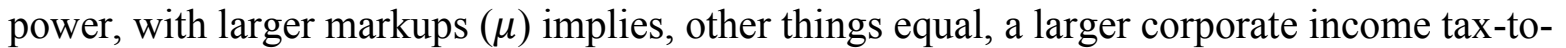

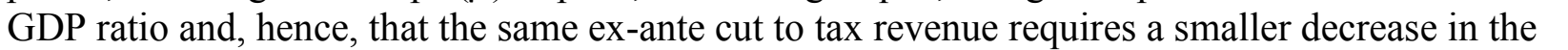

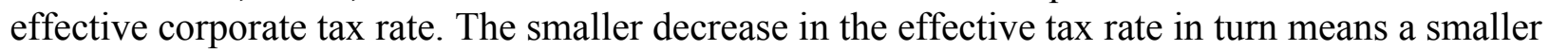

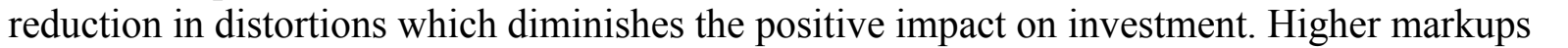

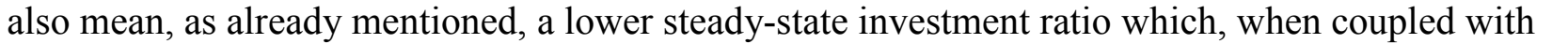

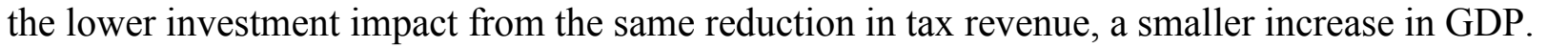
$\square$

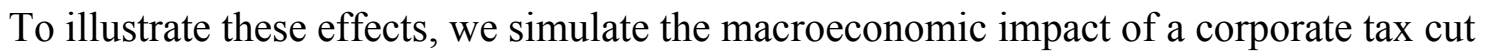

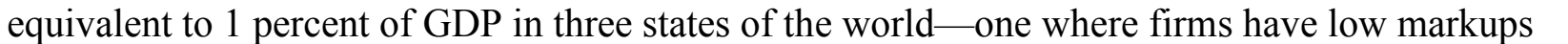

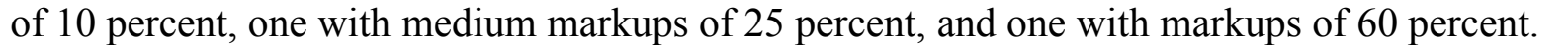

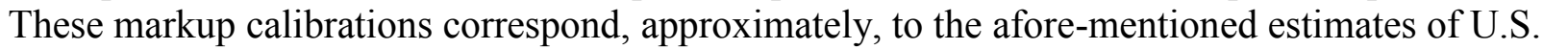

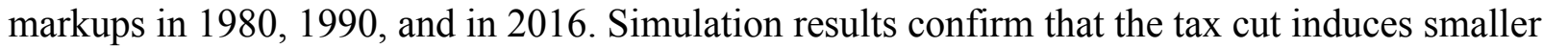

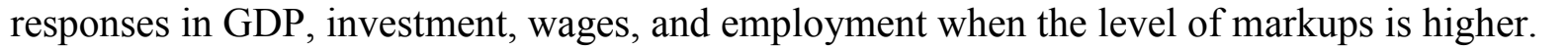

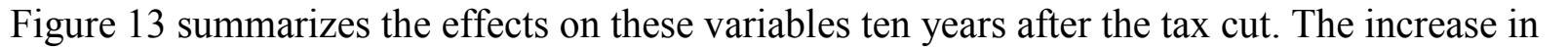

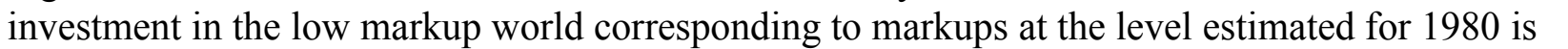




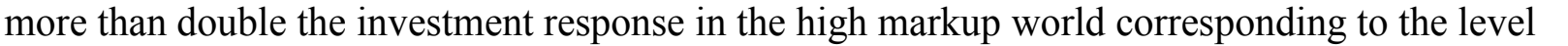

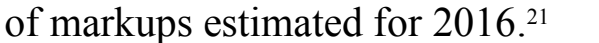

$\square$

\section{Role of Market Power: Firm-Level Empirical Estimates}

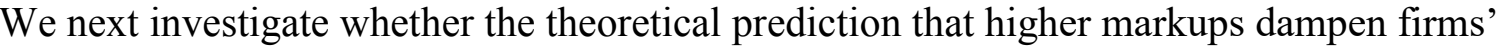

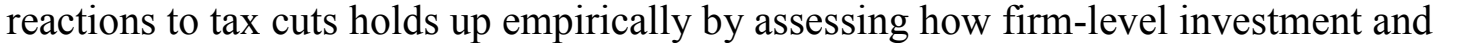

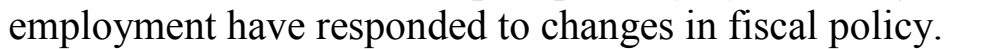

$\square$

\section{Evidence from fiscal shocks in OECD countries}

$\square$

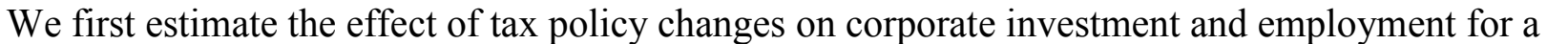

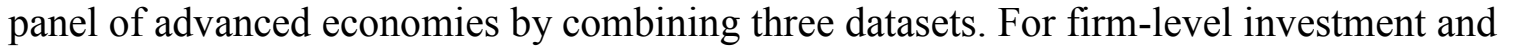

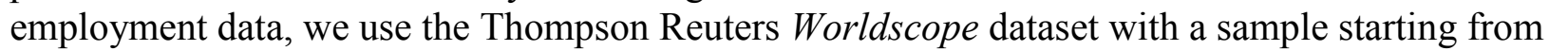

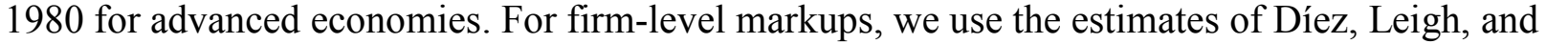

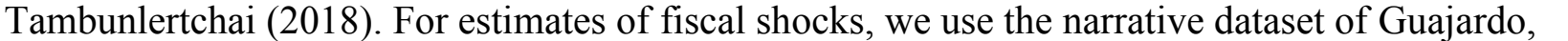

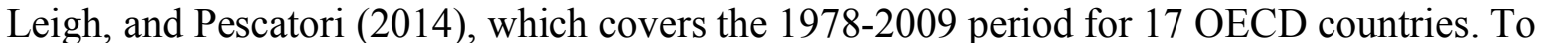

shed light on the effects of tax policy changes, we focus on the authors' series of tax $\square \square\|\square \square\|\|\| \|$

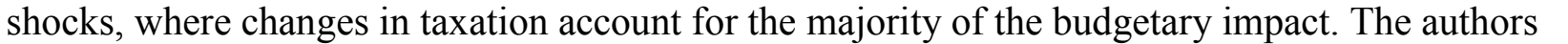

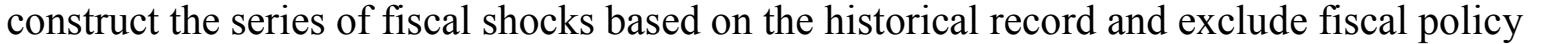

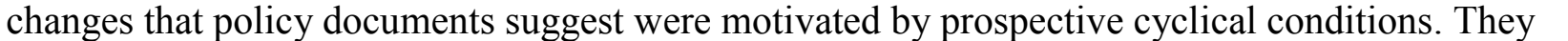

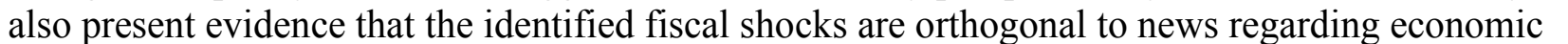

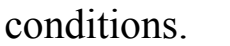

$\square$

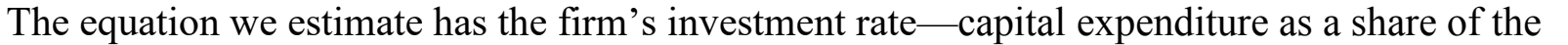

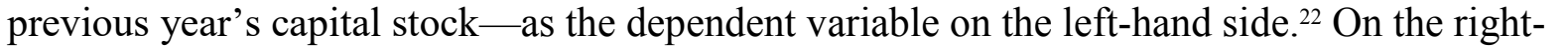

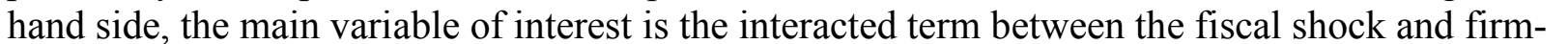

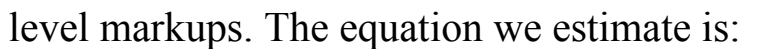

$\square$

$\square \quad Y_{i j k t}=\beta \Delta F_{k t}+\gamma\left(\Delta F_{k t} \times \ln \mu_{i j k t}\right)+\sum_{x} \theta_{x} x_{i j k t}+\sum_{i} \alpha_{i}+\sum_{t} \theta_{t}+\epsilon_{i j k t} \square$

$\square$

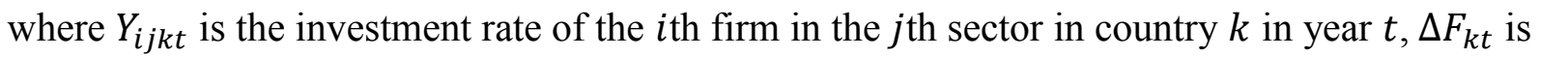

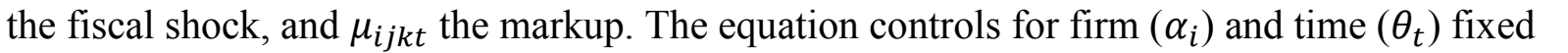

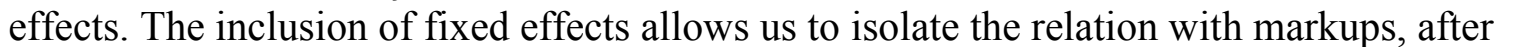

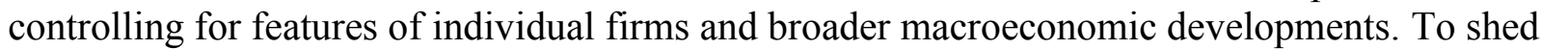

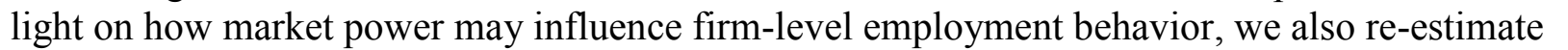

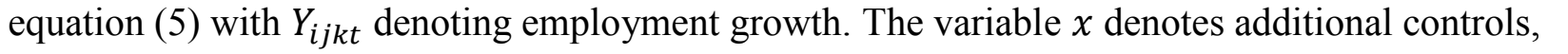

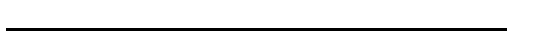

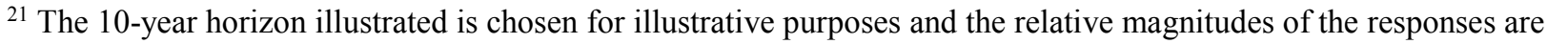

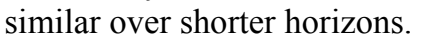

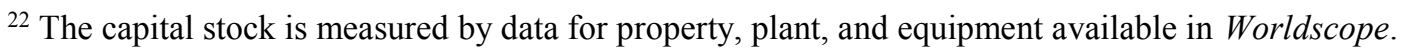




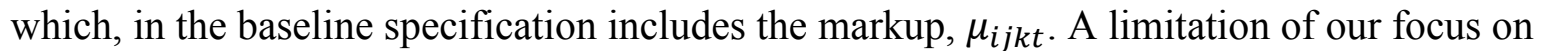

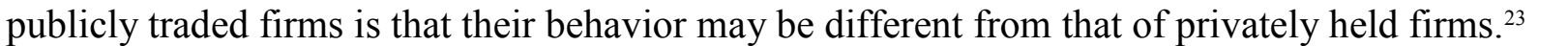
$\square$

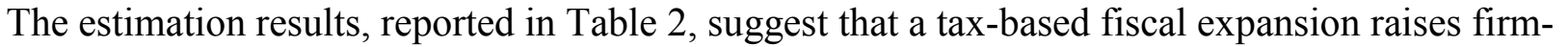

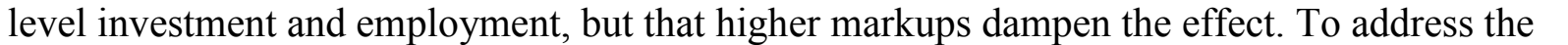

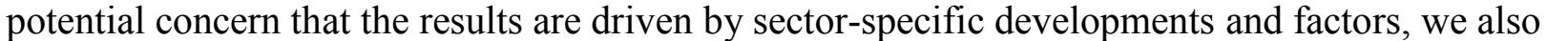

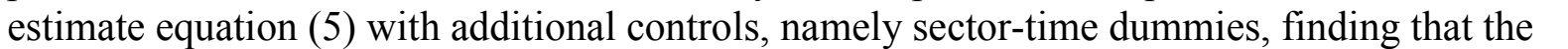

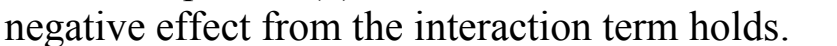

$\square$

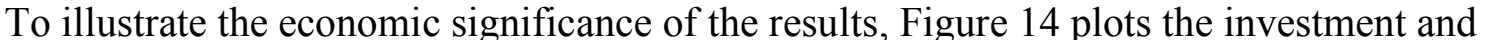

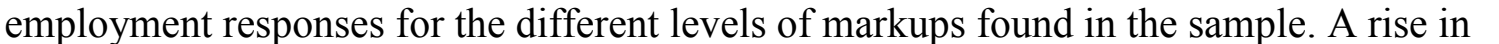

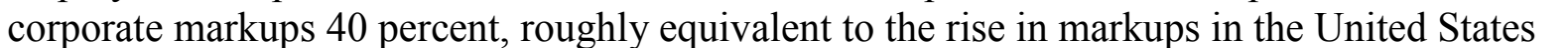

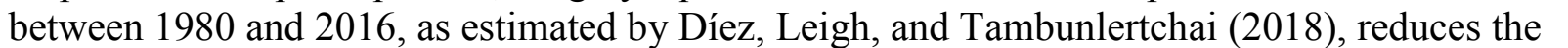

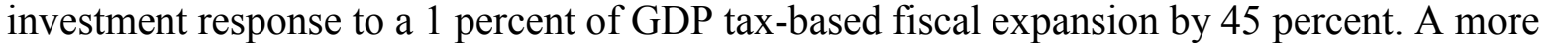

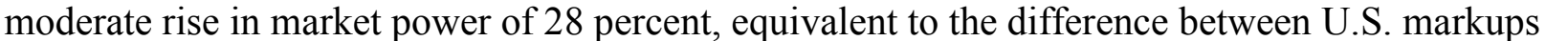

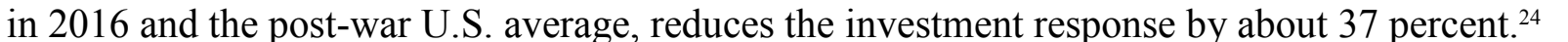

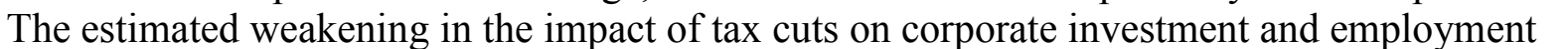

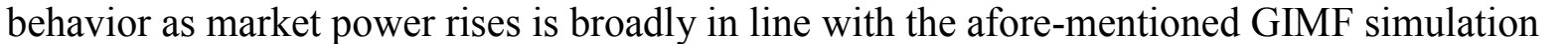
पा\|ा\|ा\|ाण

$\square$

\section{Evidence for U.S. firms in 2018}

$\square$

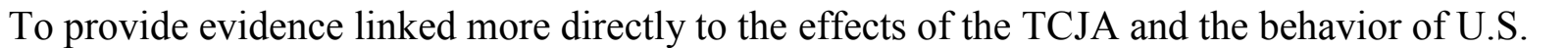

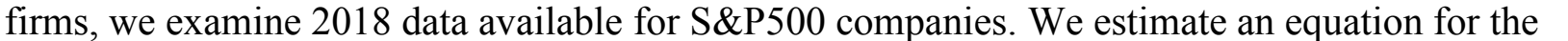

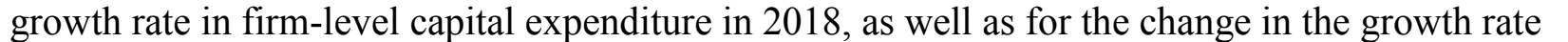

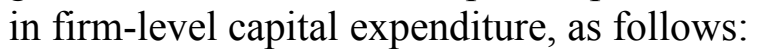

$\square$ एा $Y_{i j}=\beta \ln \mu_{i j}+\sum_{j} \alpha_{j}+\epsilon_{i j} \square$

$\square$

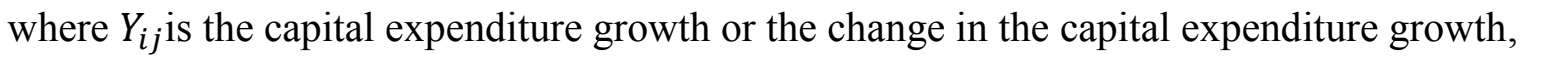

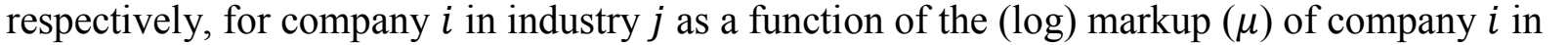

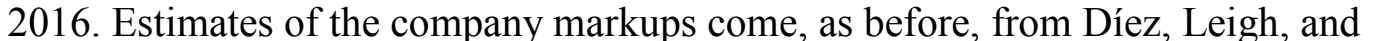

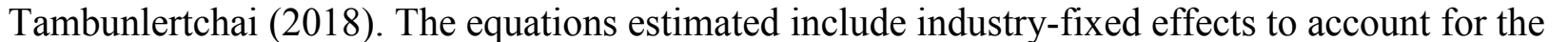

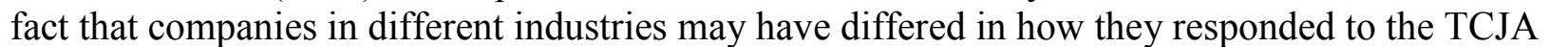

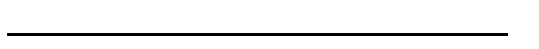

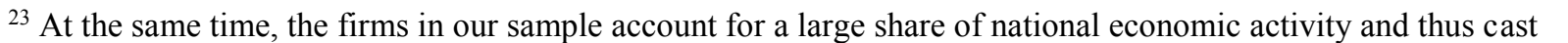

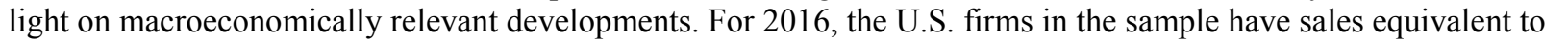

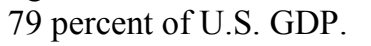

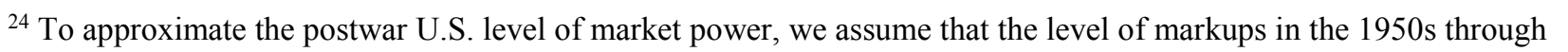

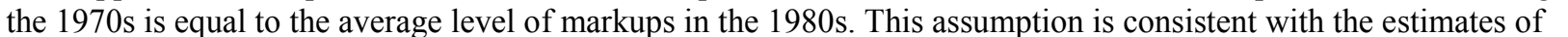

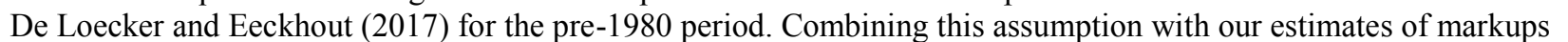

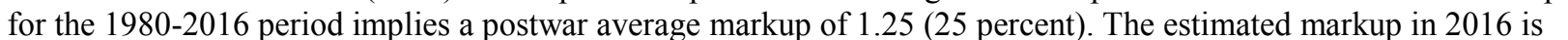

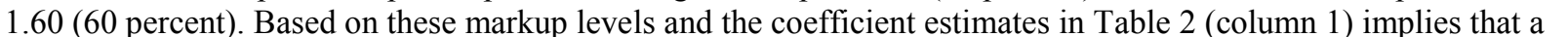

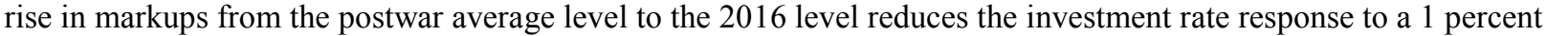

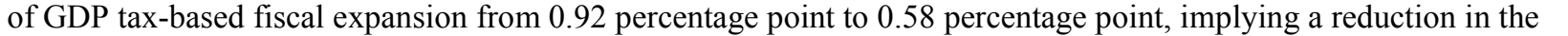

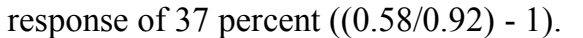




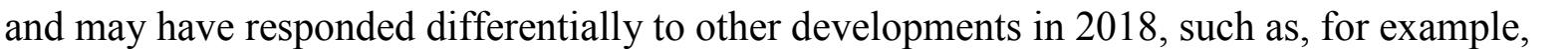

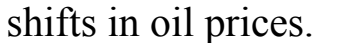

$\square$

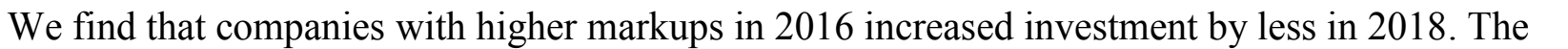

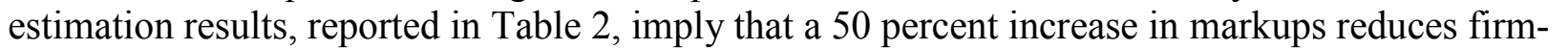

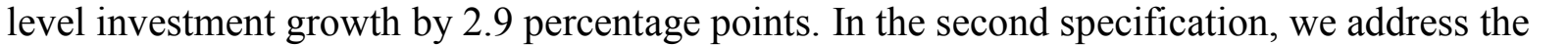

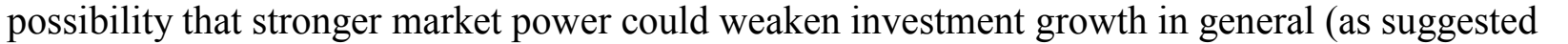

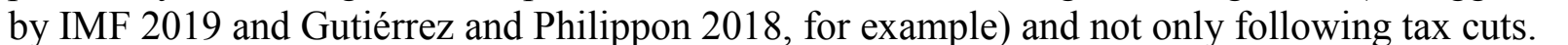

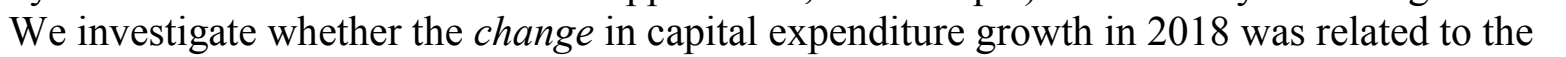

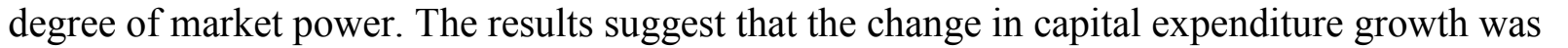

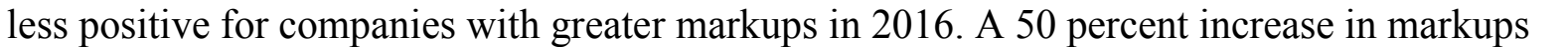

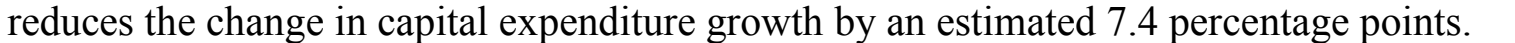
$\square$

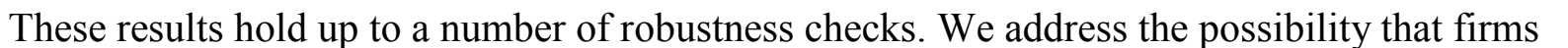

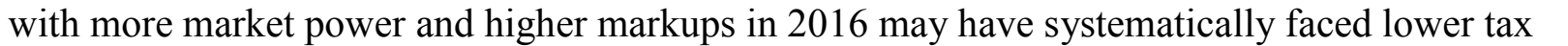

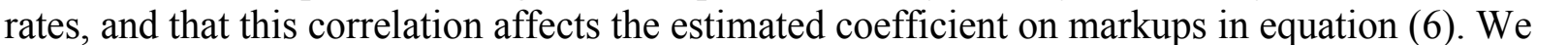

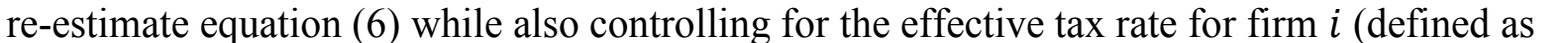

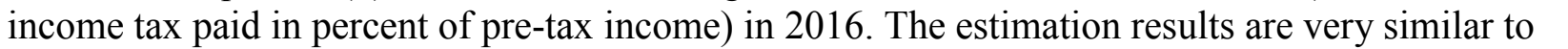
ए।

ए

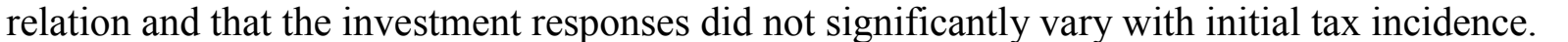

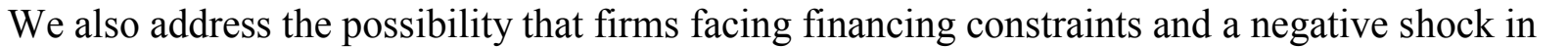

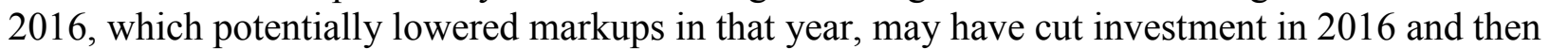

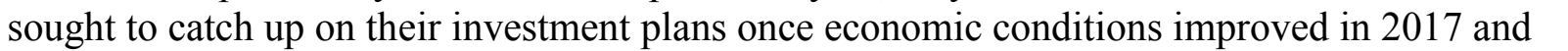

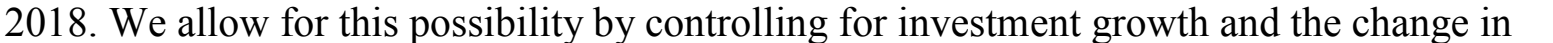
ए

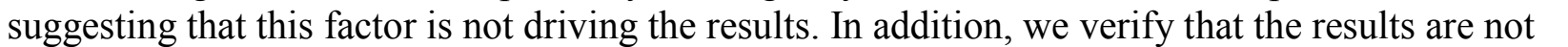

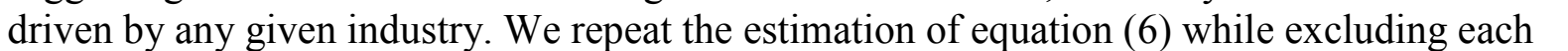

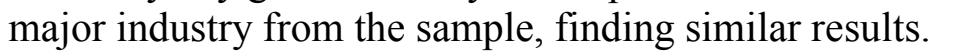

$\square$

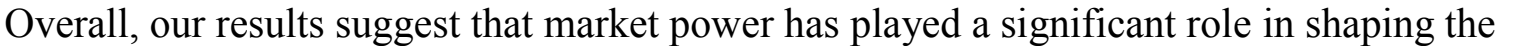

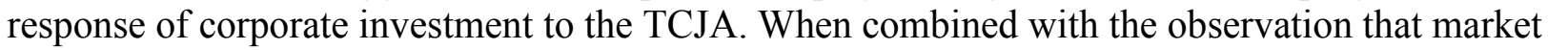

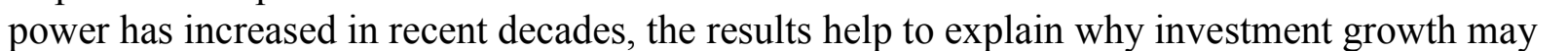

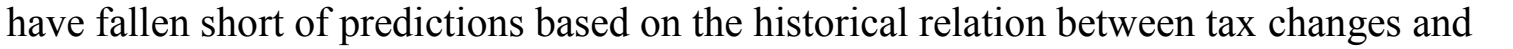

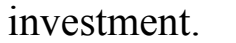

$\square$

\section{Putting Things Together}

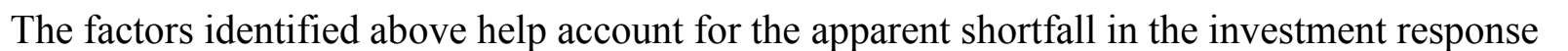

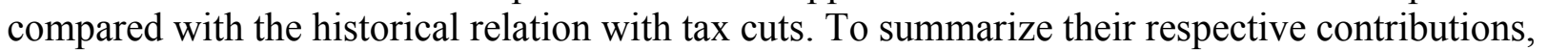

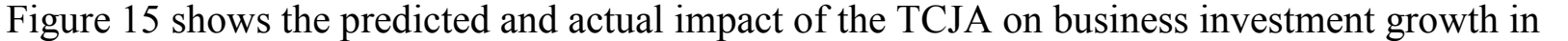

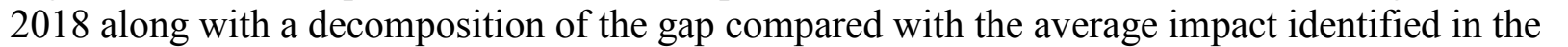

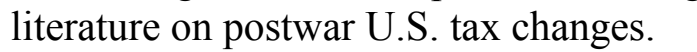

$\square$

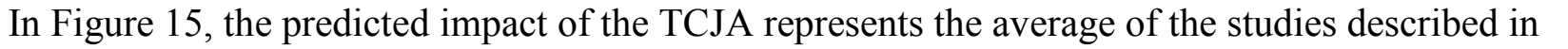

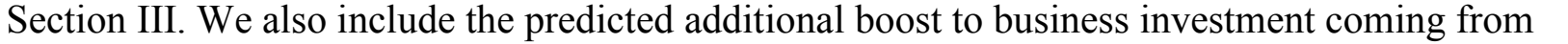

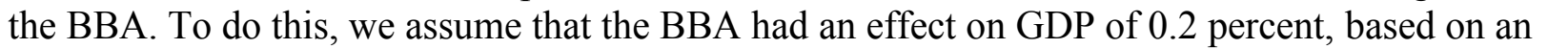




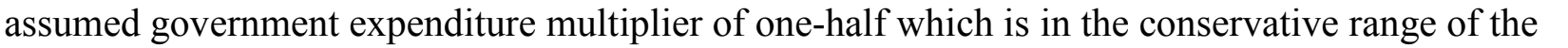

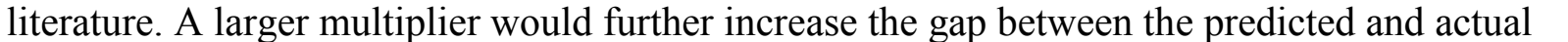

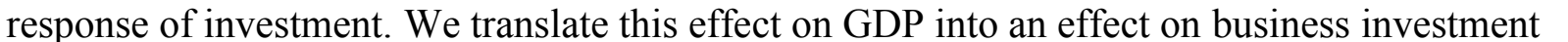

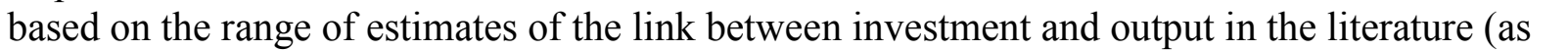

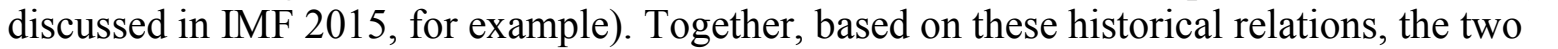

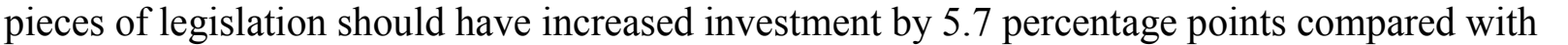

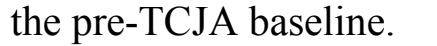

$\square$

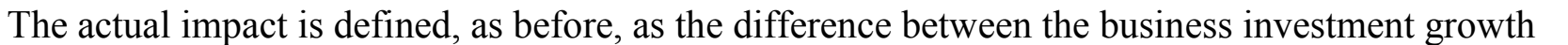

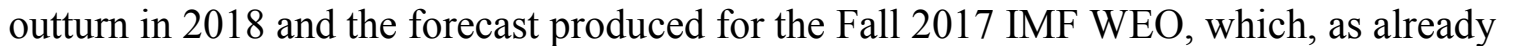

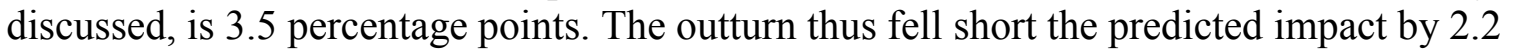

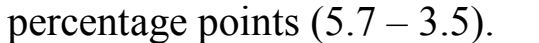

$\square$

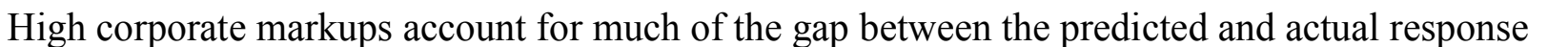

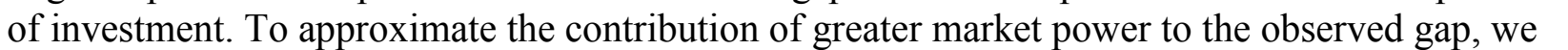

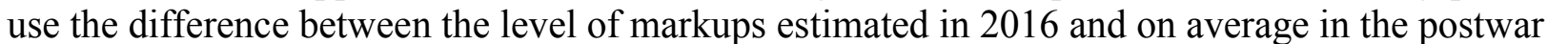

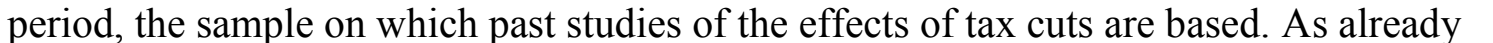

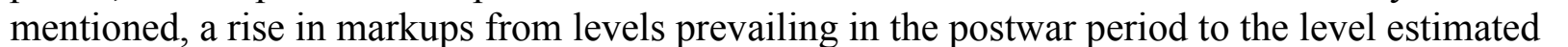

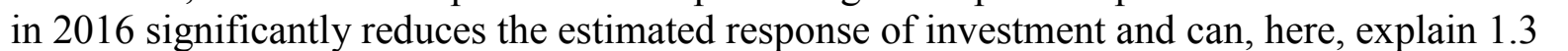

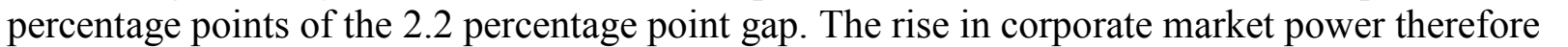

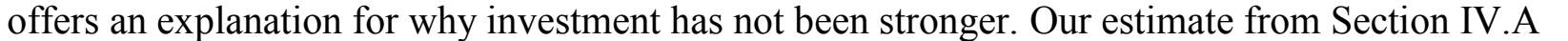

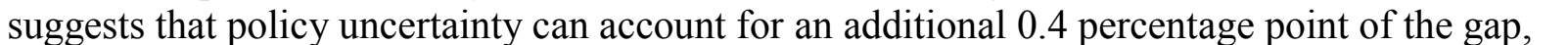

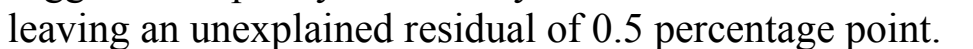

$\square$

\section{Other Factors}

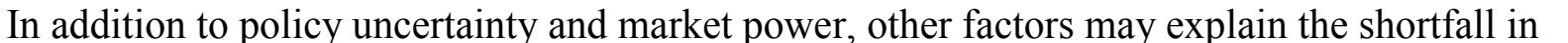

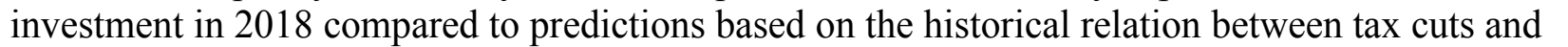
एण1⿴囗十ाणा

$\square$

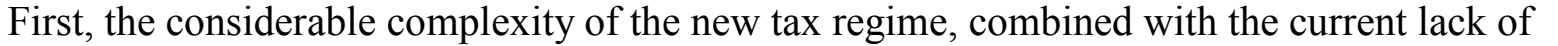

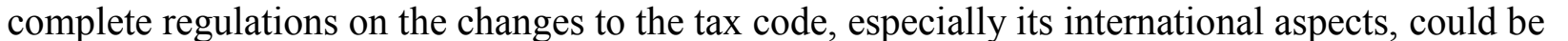

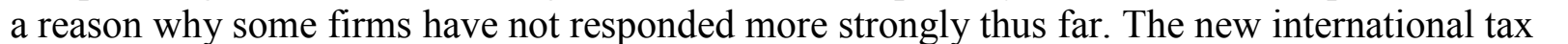

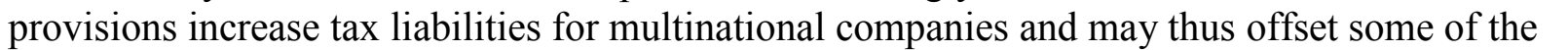

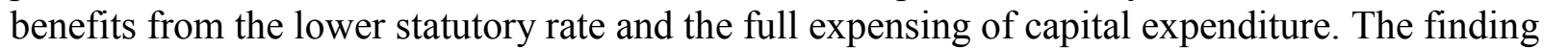

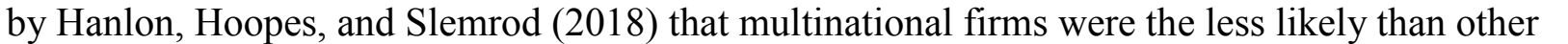

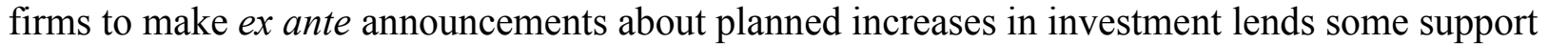

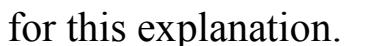

$\square$

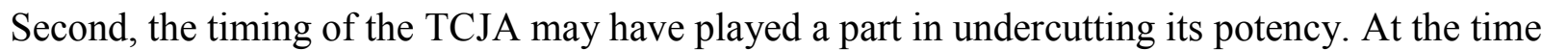

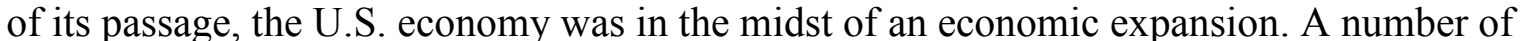

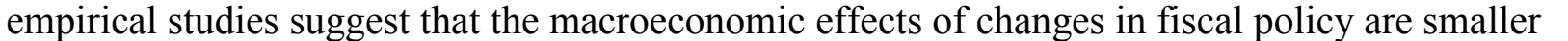

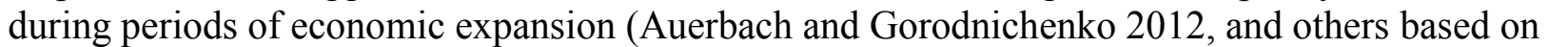

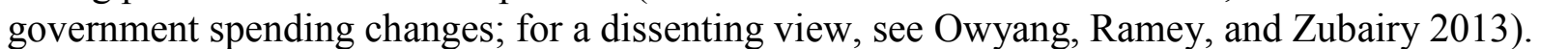

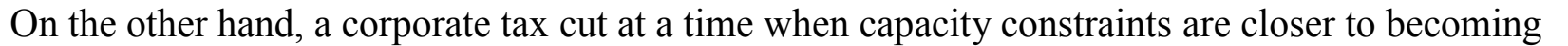

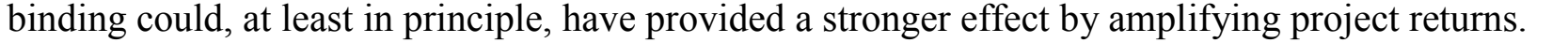
$\square$

CInternational Monetary Fund. Not for Redistribution 


\section{CONClusion}

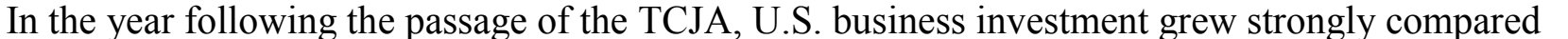
ए $\square$

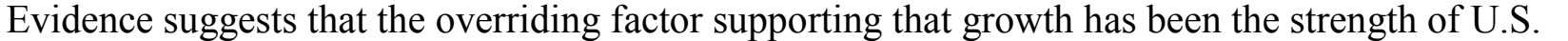

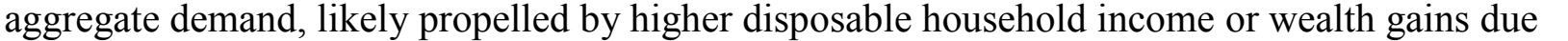

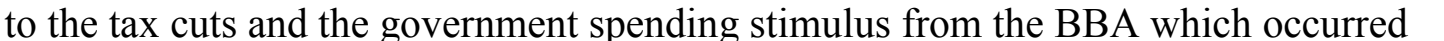

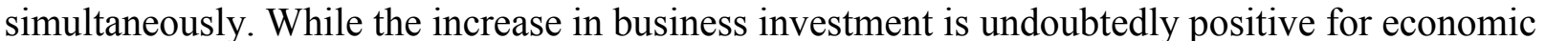

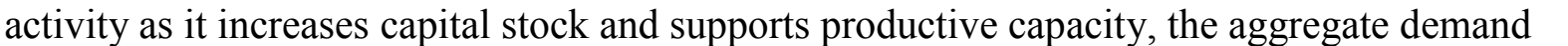

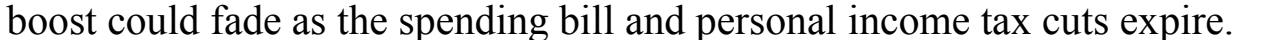

$\square$

ए

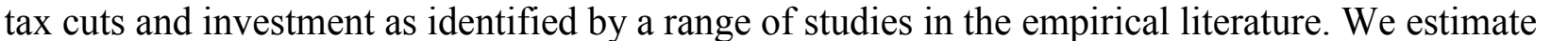

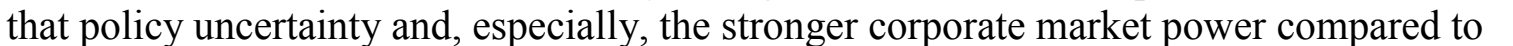

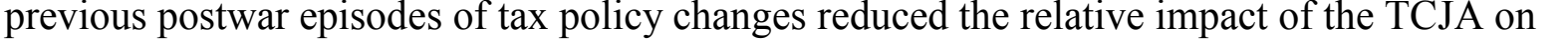

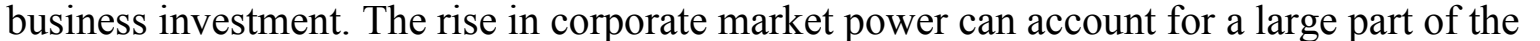

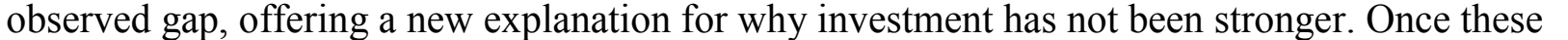

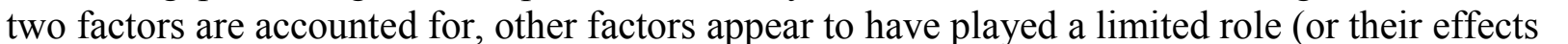

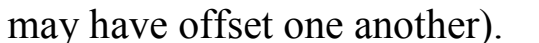

$\square$

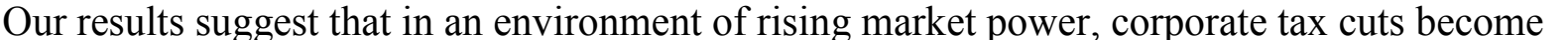
प

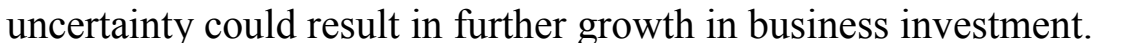

$\square$ 


\section{References}

Altig, D., N. Bloom, S. J. Davis, B. Meyer, and N. Parker, 2019. "Tariff Worries and U.S.

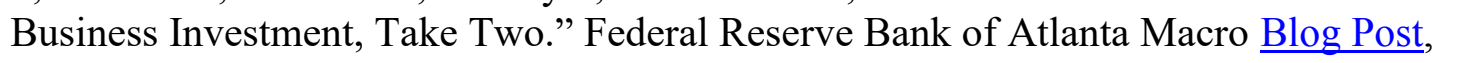

Arnon, A., 2018. "The Price of Oil is Now a Key Driver of Business Investment."

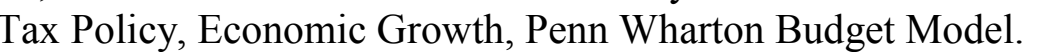

Auerbach, A. and Y. Gorodnichenko, 2012. "Measuring the Output Responses to Fiscal Policy." American Economic Journal: Economic Policy

Blanchard, O. and R. Perotti, 2002. "An Empirical Characterization of the Dynamic Effects of Changes in Government Spending and Taxes on Output." Quarterly Journal of

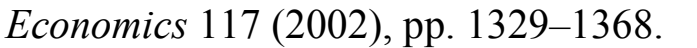

Baker, S. R., N. Bloom, and S. J. Davis, 2016. "Measuring Economic Policy Uncertainty." The Quarterly Journal of Economics

Bernanke, B. S., 1983. "Irreversibility, Uncertainty, and Cyclical Investment." The Quarterly Journal of Economics $\square \square \square \square \square-\square \square$

Bloom, N., S. Bond, and J. Van Reenen, 2007. "Uncertainty and Investment Dynamics.” The

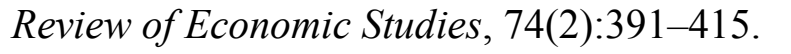

Caldara, D. and C. Kamps, 2017. "The Analytics of SVARs: A Unified Framework to Measure

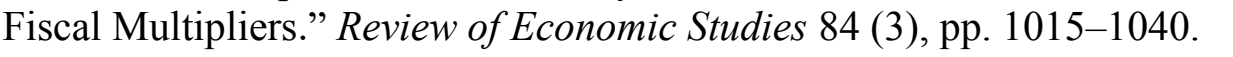

Chalk, N., M. Keen, and V. J. Perry, 2018. “The Tax Cuts and Jobs Act: An Appraisal.”

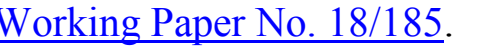

Congressional Budget Office, 2018. “The Budget and Economic Outlook: 2018 to 2028," April $\square \square \square$

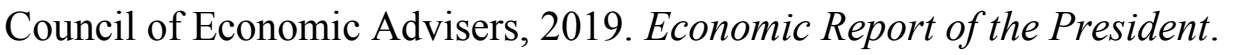

De Loecker, J. and J. Eeckhout, 2018. “Global Market Power.” NBER Working Paper No. 24768

De Loecker, J., and J. Eeckhout, 2017. "The Rise of Market Power and the Macroeconomic Implications," NBER Working Paper No. 23687.

WI, F., D. Leigh, and S. Tambunlertchai, 2018. "Global Market Power and Its Macroeco Implications." 


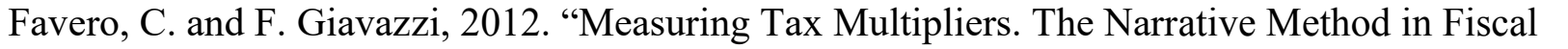

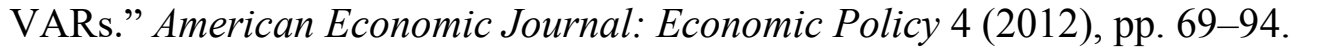

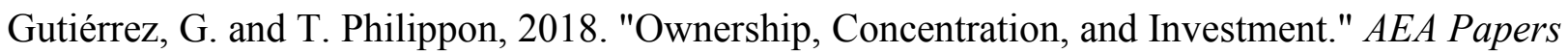
and Proceedings एणाएाएणए।

$\square$

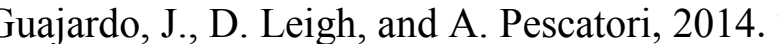

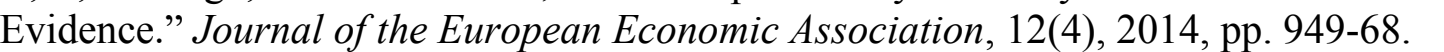

Hanlon, M., J. L. Hoopes, and J. Slemrod, 2018. “Tax Reform Made Me Do It!” NBER Working

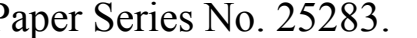

$\square \square$ dley, K. and N. Limão, 2015. "Trade and Investment Under Policy Uncertainty: Theory and

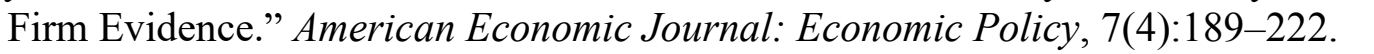

IMF, 2015. "Private Investment: What's the Holdup?” World Economic Outlook $\square \square \square$

IMF, 2019. "The Rise of Corporate Market Power and Its Macroeconomic Effects" World

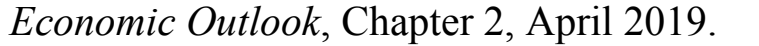

Jorgenson, D. W., and C. D. Siebert, 1968. "Optimal Capital Accumulation and Corporate Investment Behavior." Journal of Political Economy

Joint Committee on Taxation, 2017. "Estimated Budget Effects of the Conference Agreement for H.R.1, 'The Tax Cuts and Jobs Act.'” $\square$

Krugman, P., 2018. “Why Was Trump's Tax Cut a Fizzle?” New York Times

$\square \square$ hof, M., D. Laxton, S. Mursula, and D. Muir, 2010. "The Global Integrated Monetary and

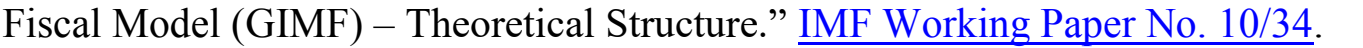

Mertens, K., 2018. "The Near Term Growth Impact of the Tax Cuts and Jobs Act," Federal

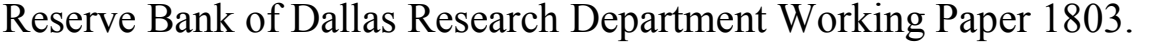

$\square$

Mertens, K. and M. Ravn, 2012. "Empirical Evidence on the Aggregate Effects of Anticipated and Unanticipated US Tax Policy Shocks", American Economic Journal: Economic Policy

Mertens, K. and M. O. Ravn, 2013, "The Dynamic Effects of Personal and Corporate Income Tax Changes in the United States,” American Economic Review 2013, 103(4): 1212$\square 11 \mathrm{I}$

Mertens, K. and M. Ravn, 2014. "A Reconciliation of SVAR and Narrative Estimates $\square \square \square$

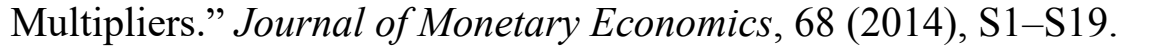


Nation Association for Business Economics, 2018. "NABE Business Conditions Survey" $\square$

National Federation of Independent Business Research Center, 2018. "Small Business

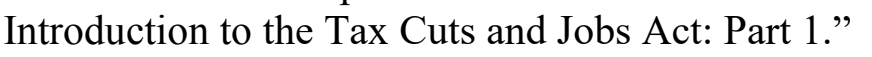

Oliner, S., G. Rudebusch, and D. Sichel, 1995. "New and Old Models of Business Investment: A Comparison of Forecasting Performance." Journal of Money, Credit and Banking

$\square$

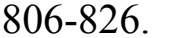

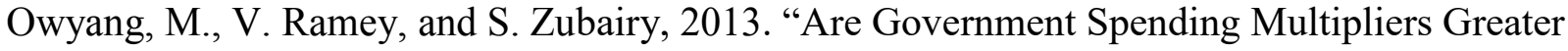

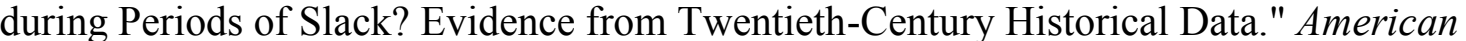
Economic Review

Panousi, V and D. Papanikolaou, 2012. "Investment, Idiosyncratic Risk, and Ownership," The Journal of Finance $\mathrm{m} \square \mathrm{\square m}$

Romer, C. D. and D. H. Romer, 2010. "The Macroeconomic Effects of Tax Changes: Estimates Based on a New Measure of Fiscal Shocks", American Economic Review

Smith, Karl W., 2018, “It's Not a Trump Boom, It's an Oil and Gas Boom,” 


\section{Figure 1. Evolution of Forecasts of Growth for 2018}

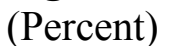

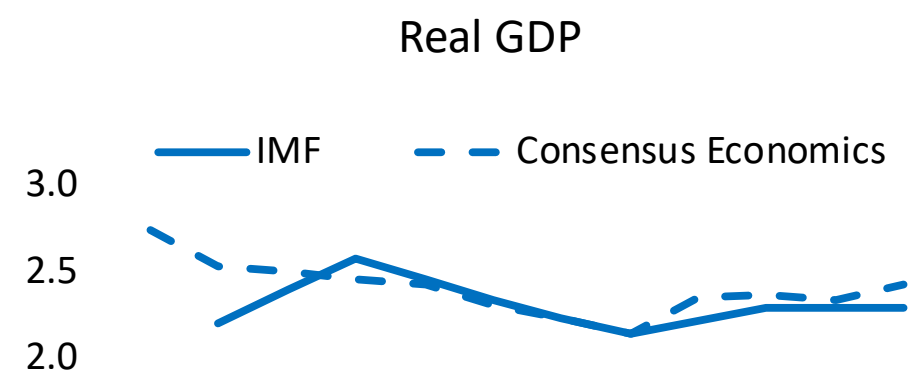

\section{5}

1.0

0.5

0.0

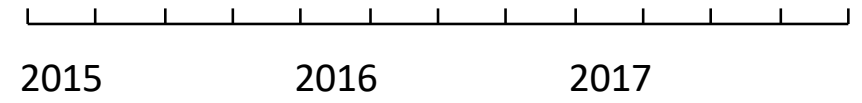

$\square$

Real Business Investment

5.0

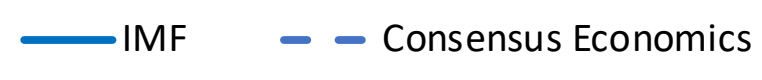

4.0

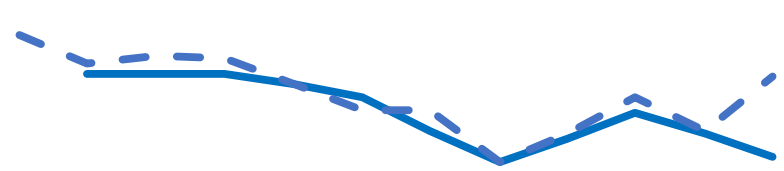

3.0

2.0

1.0

0.0

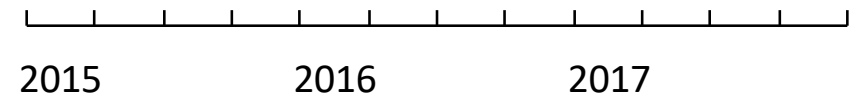


Figure 2. Real Private Fixed Investment: United States and Other Advanced Economies

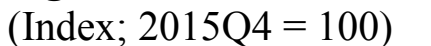
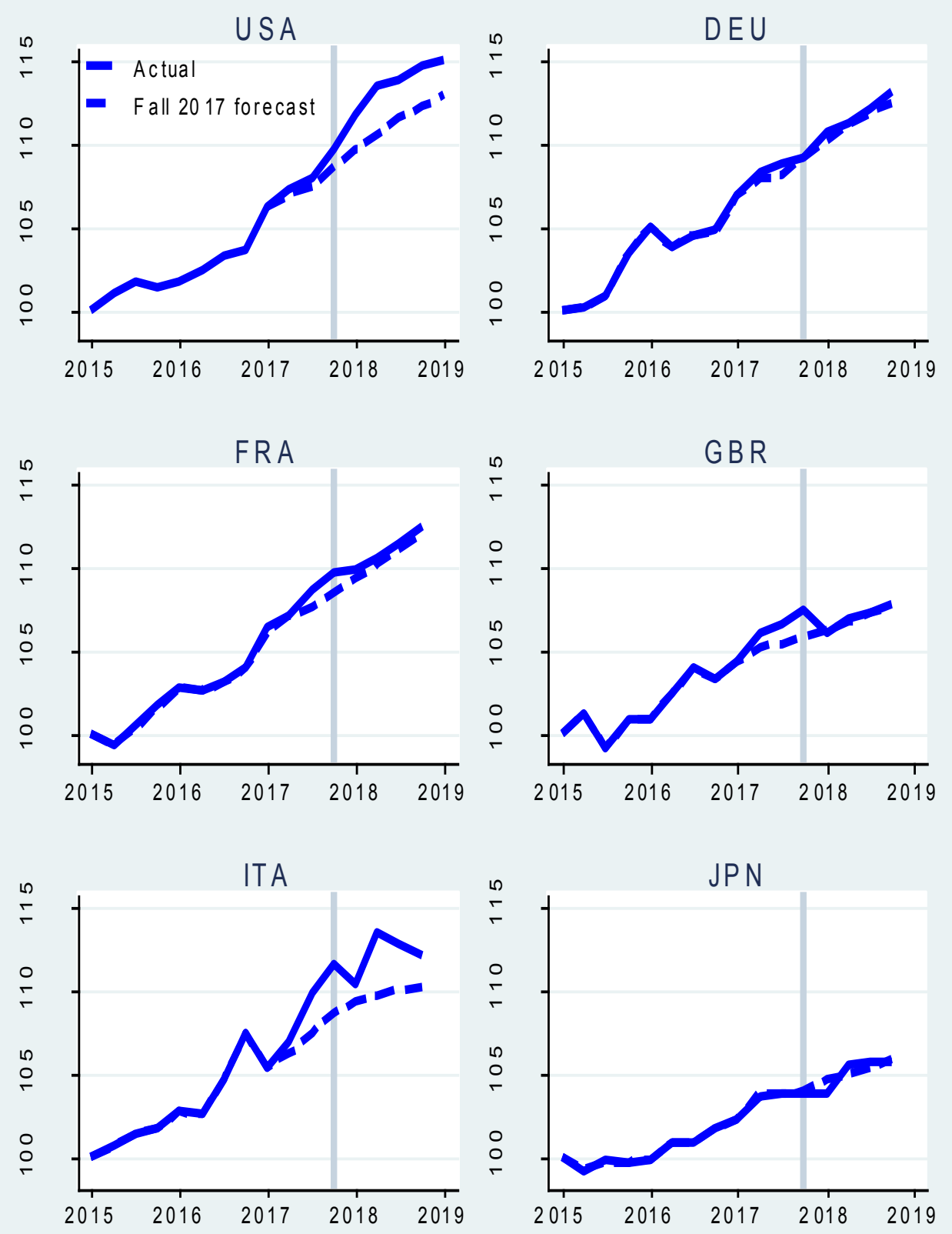
Figure 3. U.S. Real Private Fixed Investment

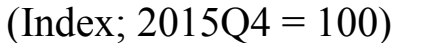
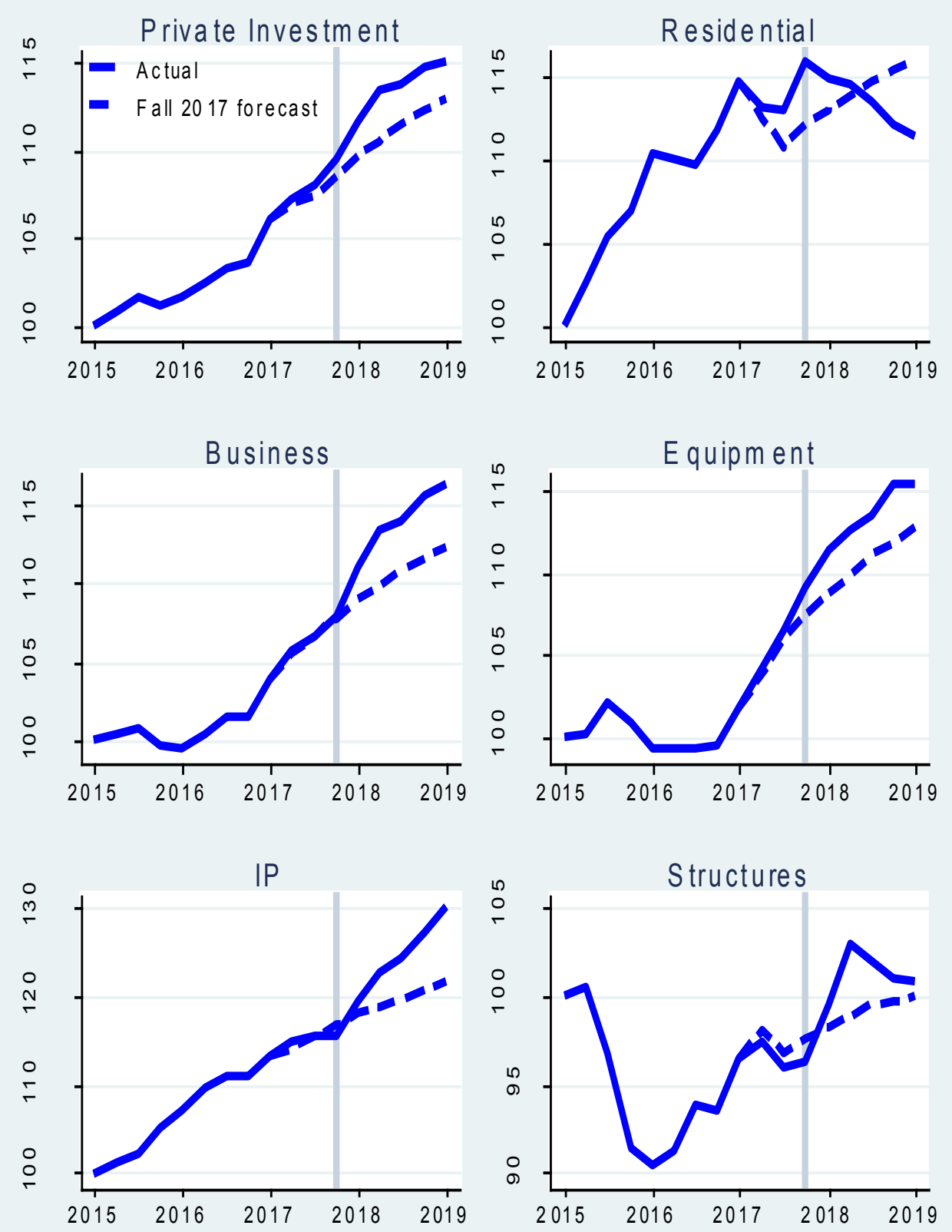
Figure 4. Business Investment Level: Deviations from Forecast

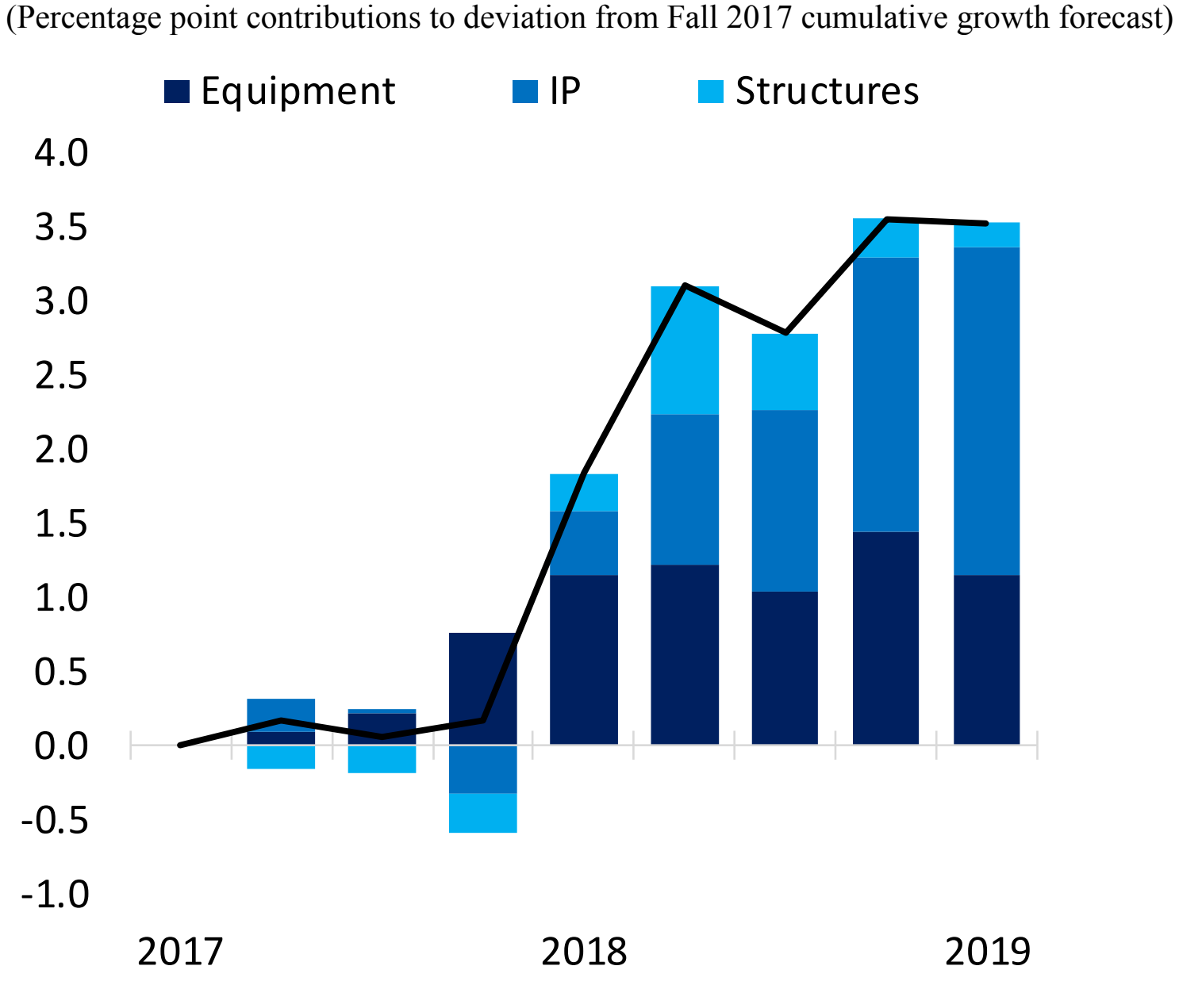

Source: National Income and Product Accounts and authors' calculations.

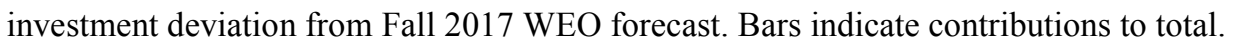


Figure 5. Business Investment: Oil vs. Non-oil Sector

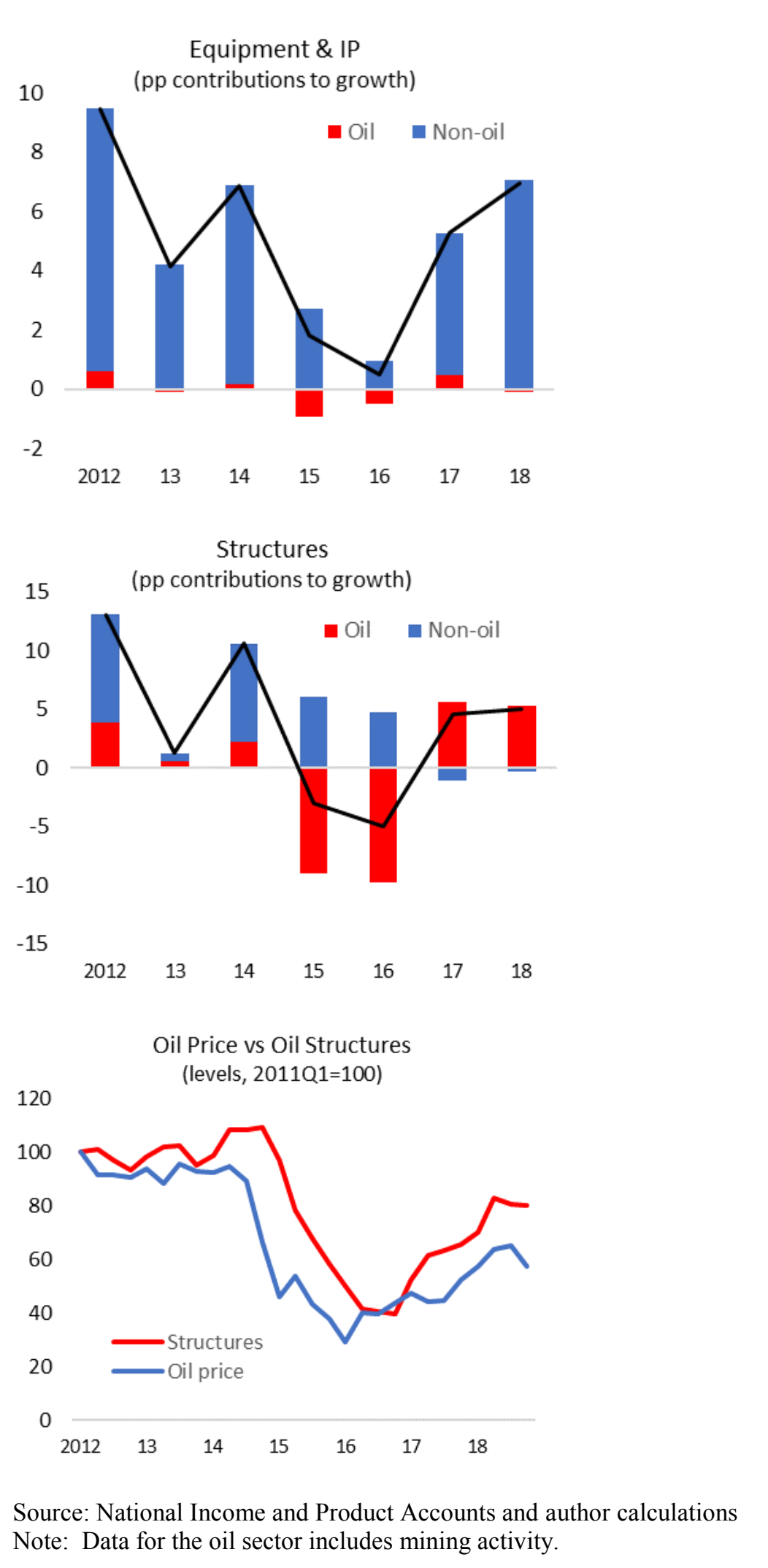

CInternational Monetary Fund. Not for Redistribution 
Figure 6. Accelerator Model: Real Business Investment

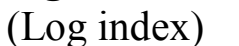

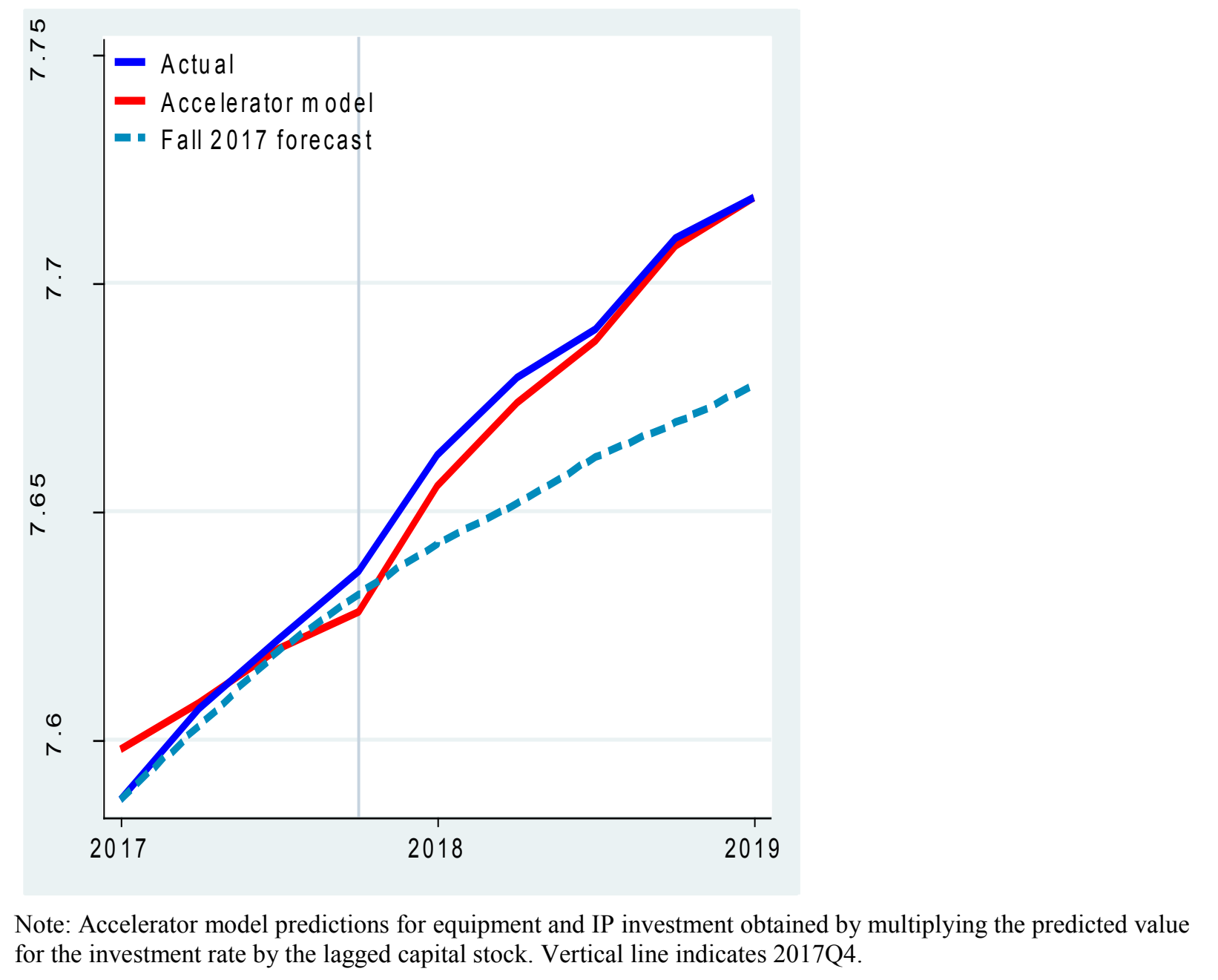

CInternational Monetary Fund. Not for Redistribution 
Figure 7. Firm Survey Responses
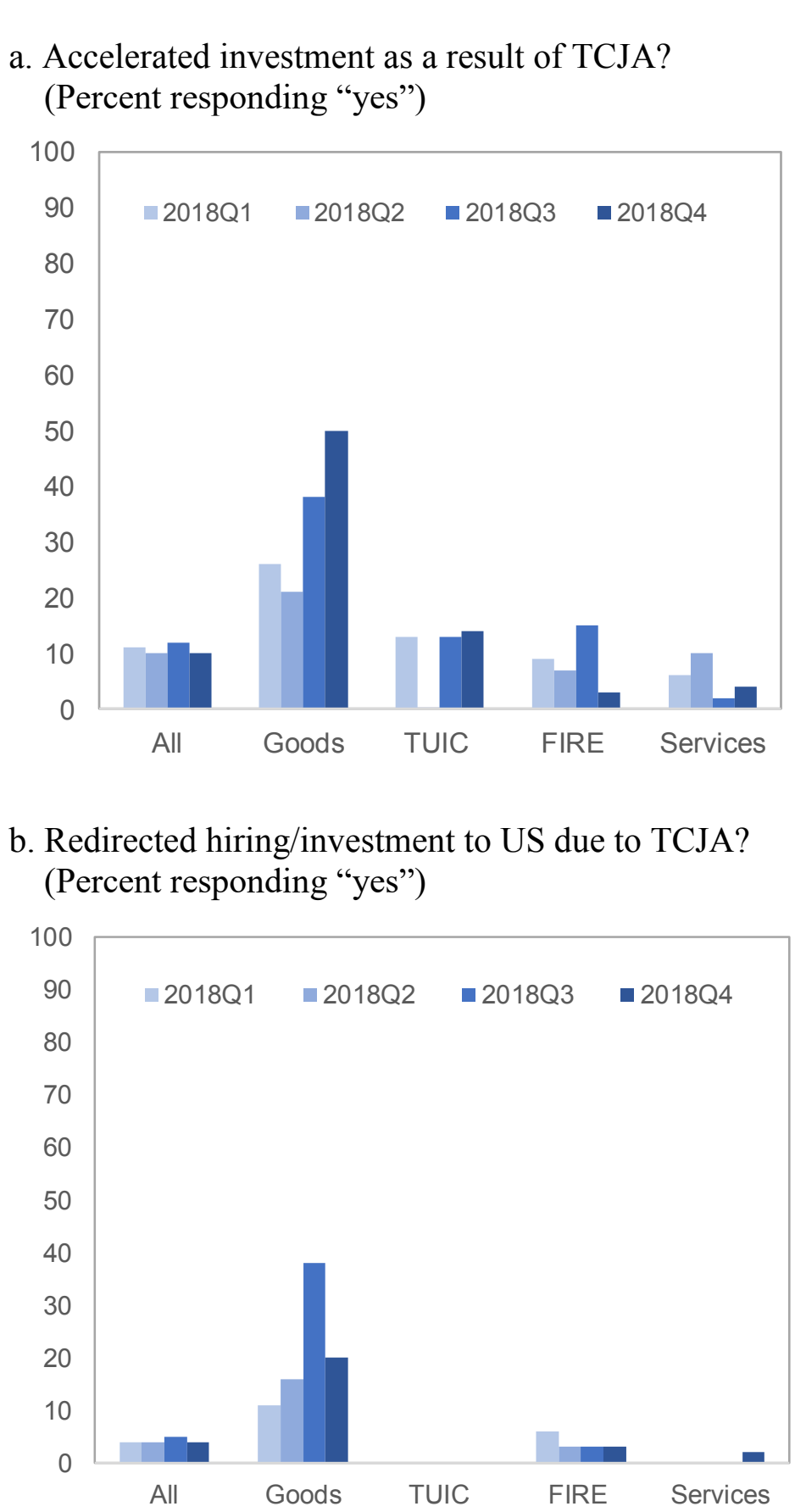

Source: National Association of Business Economics’ Business Conditions Survey $\square$

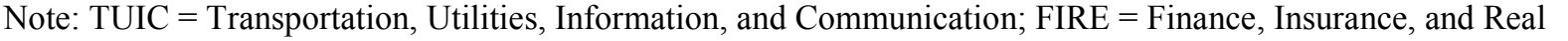
प्राणाणा 


\section{Figure 8. Use of Incremental Cash Since TCJA}

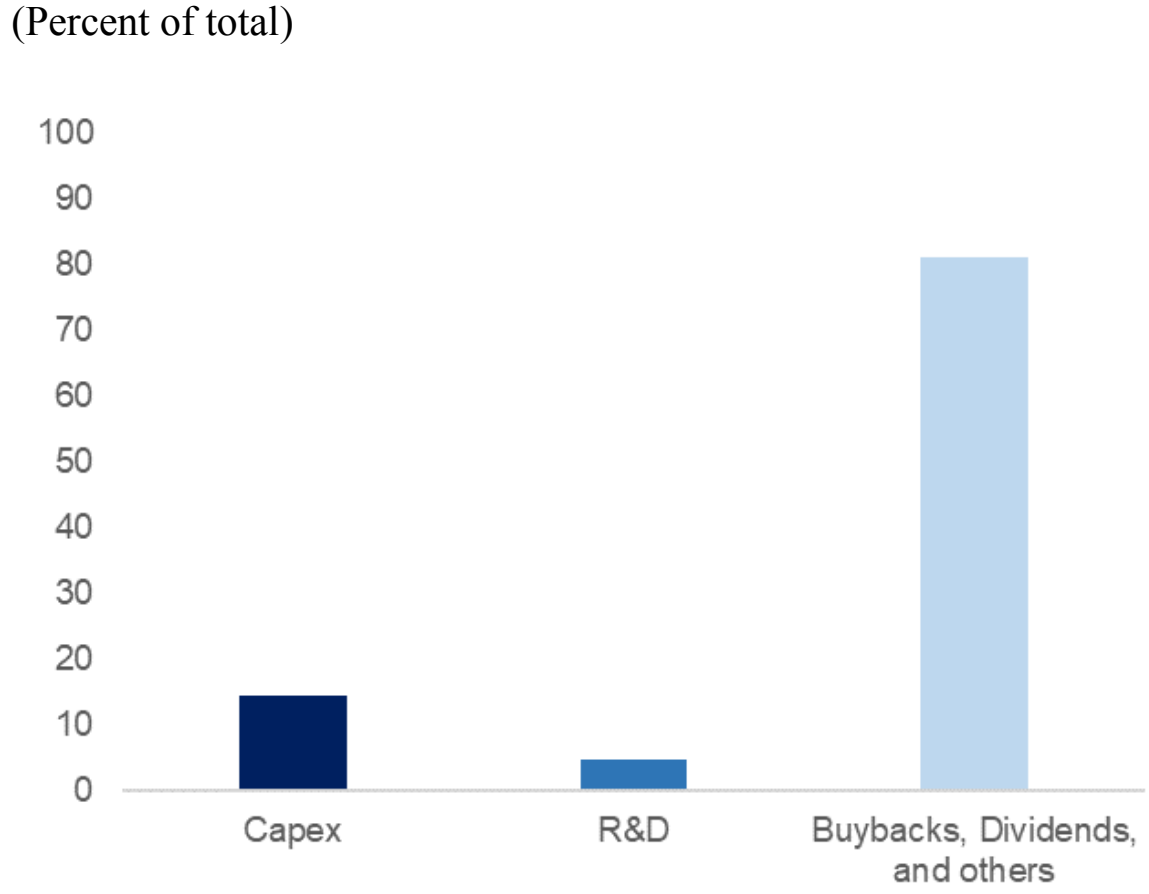

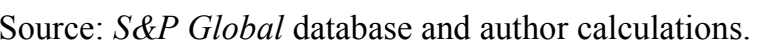


Figure 9. Impact of Tax Cuts and Jobs Act on 2018 Growth: Actual vs. Predicted Based on Existing Empirical Estimates $\square$

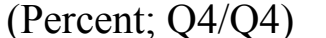

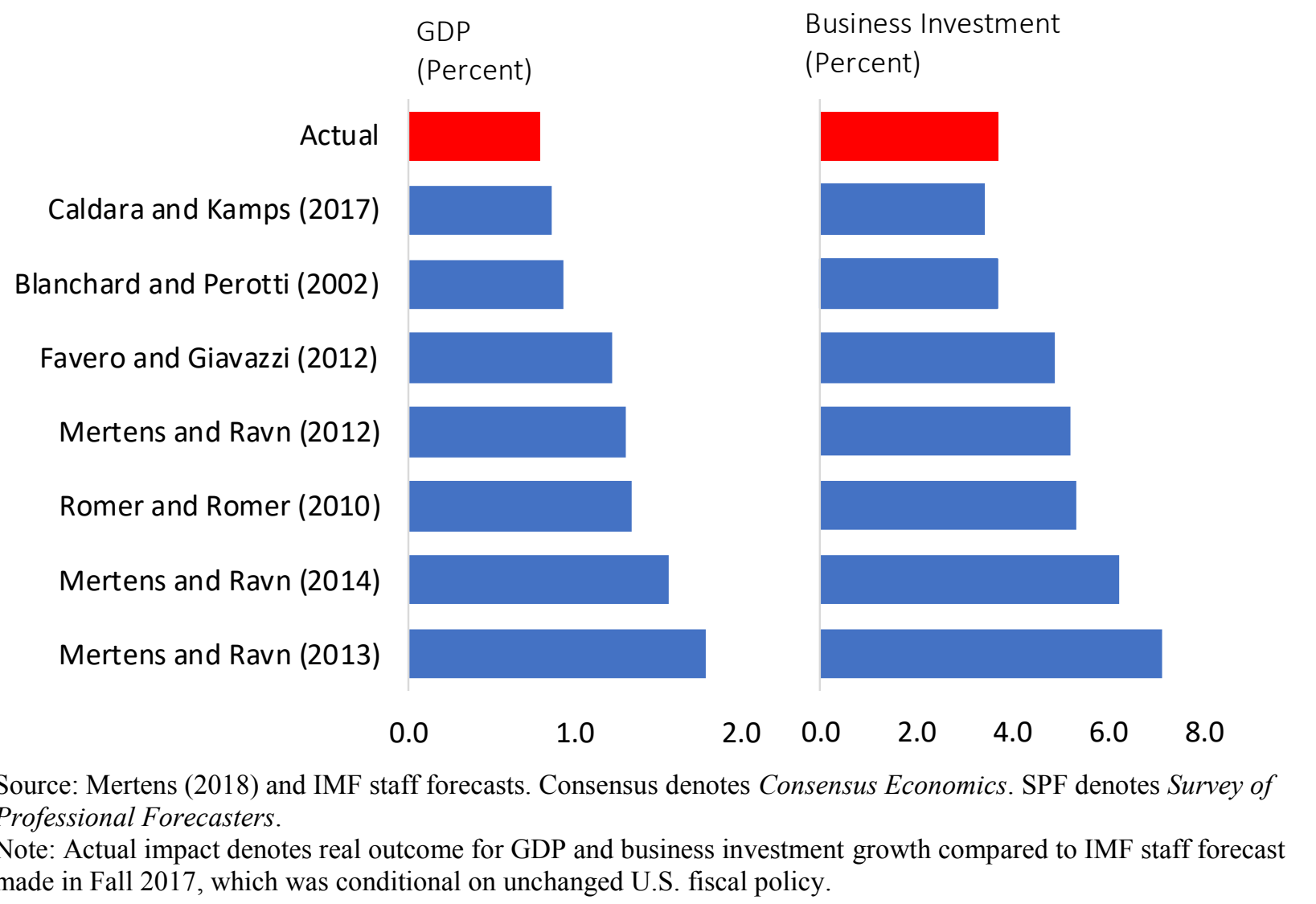


Figure 10. Trade Policy Uncertainty and Economic Policy Uncertainty

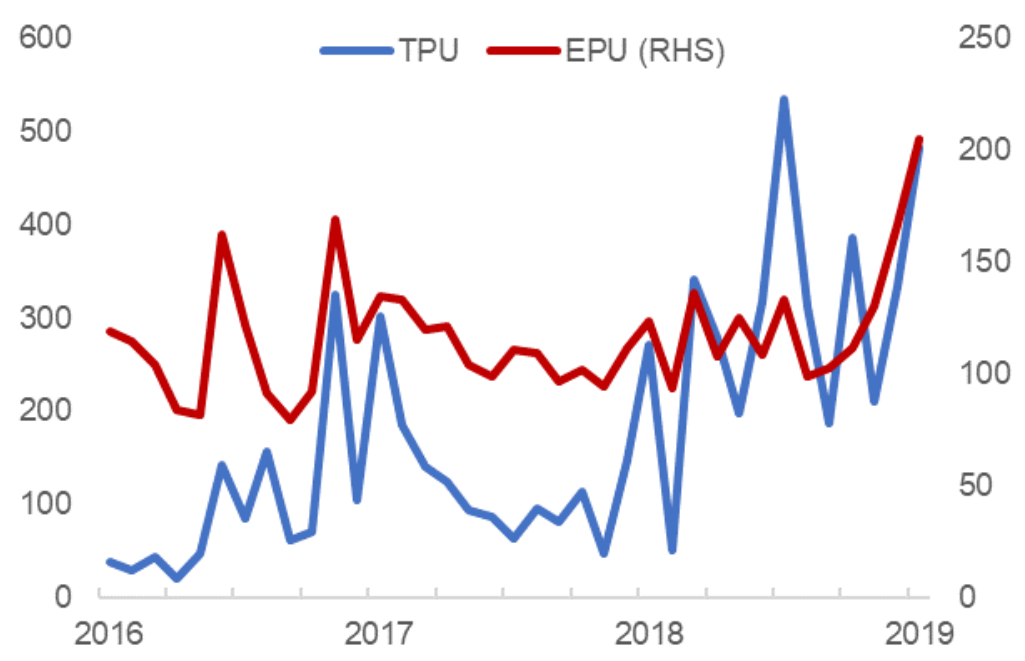

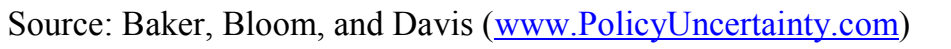

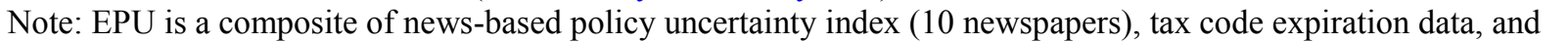

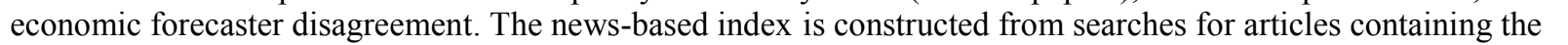

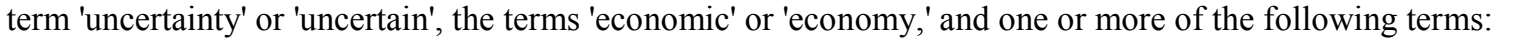
पा

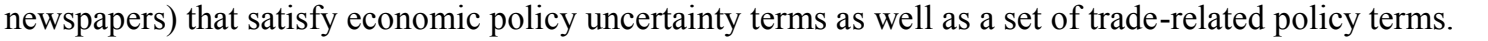

Figure 11. Estimated Effect of Economic Policy Uncertainty on Investment in 2018

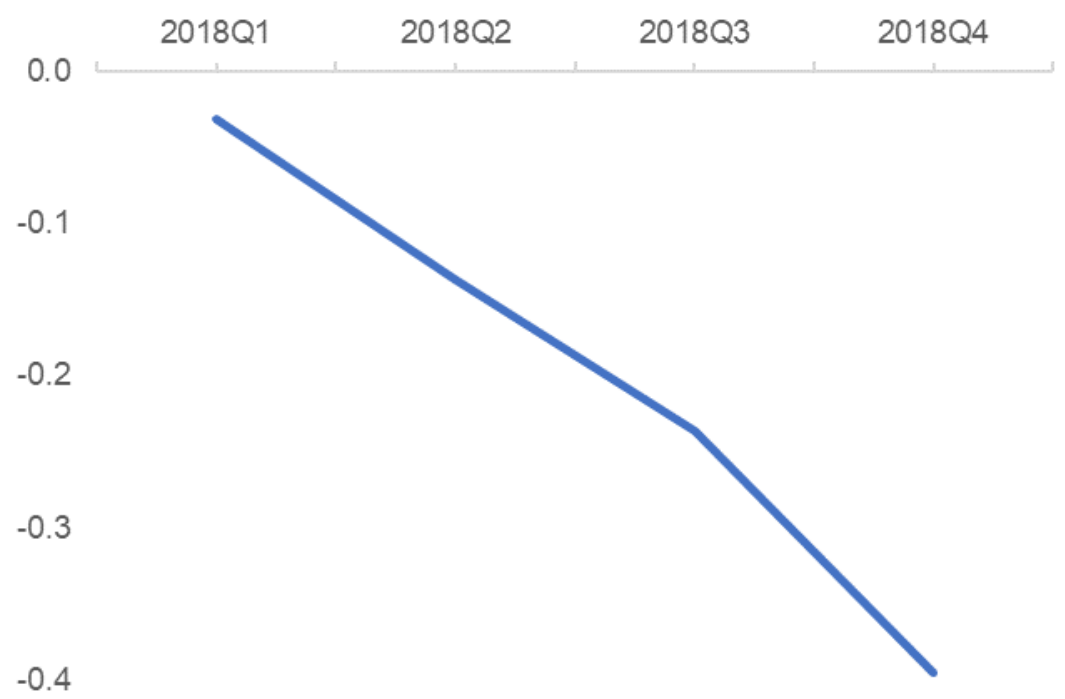

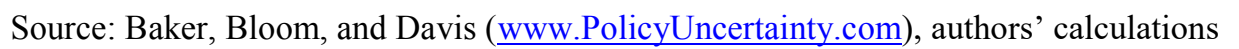

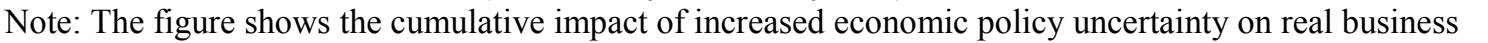

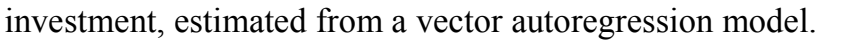


Figure 12. United States: Evolution of Estimated Markups

(Sales-weighted mean for all publicly listed firms) $\square$

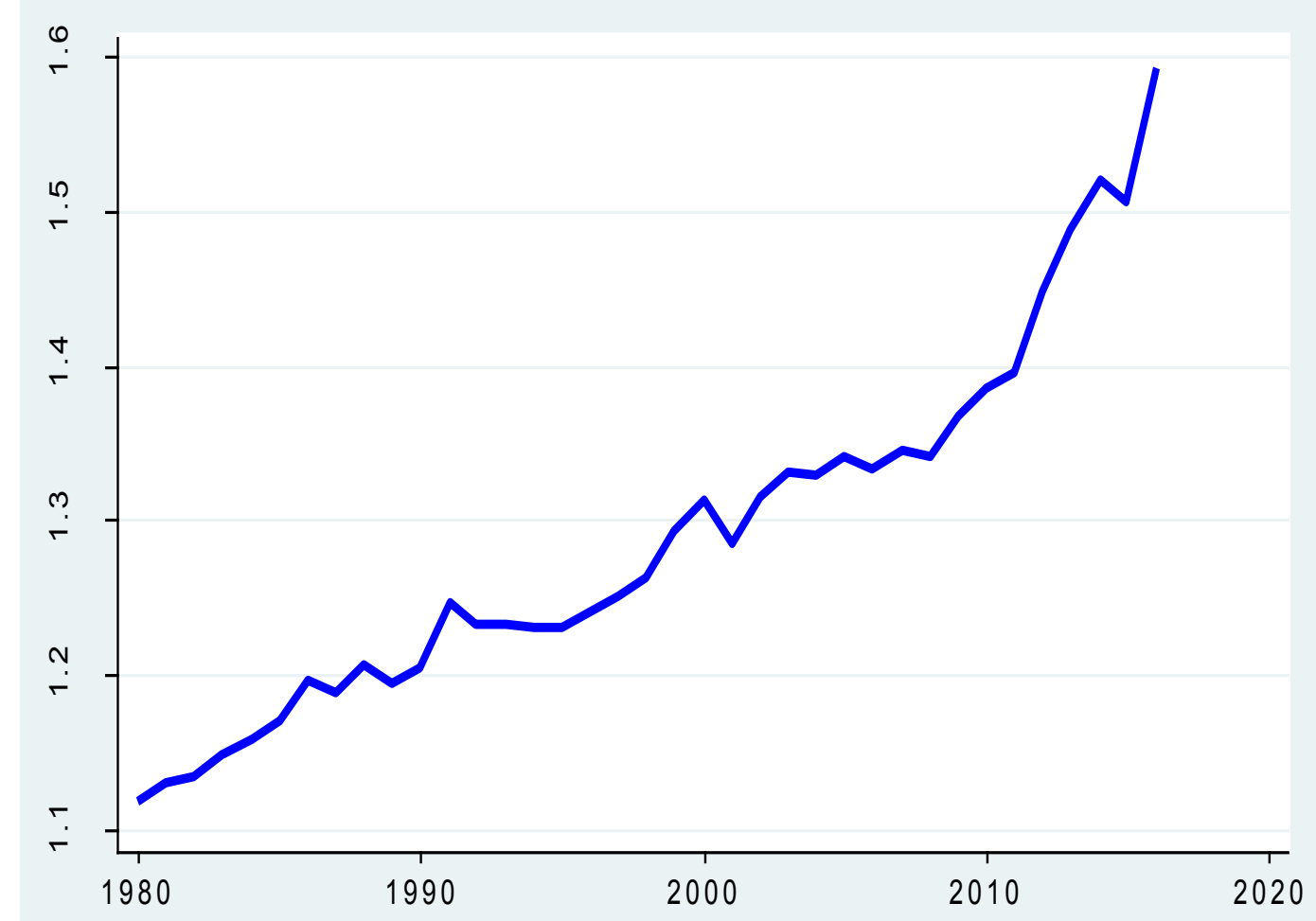

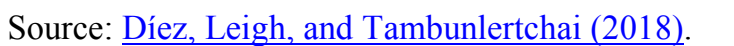


Figure 13. Macroeconomic Impact of 1 Percent of GDP Corporate Income Tax Cut

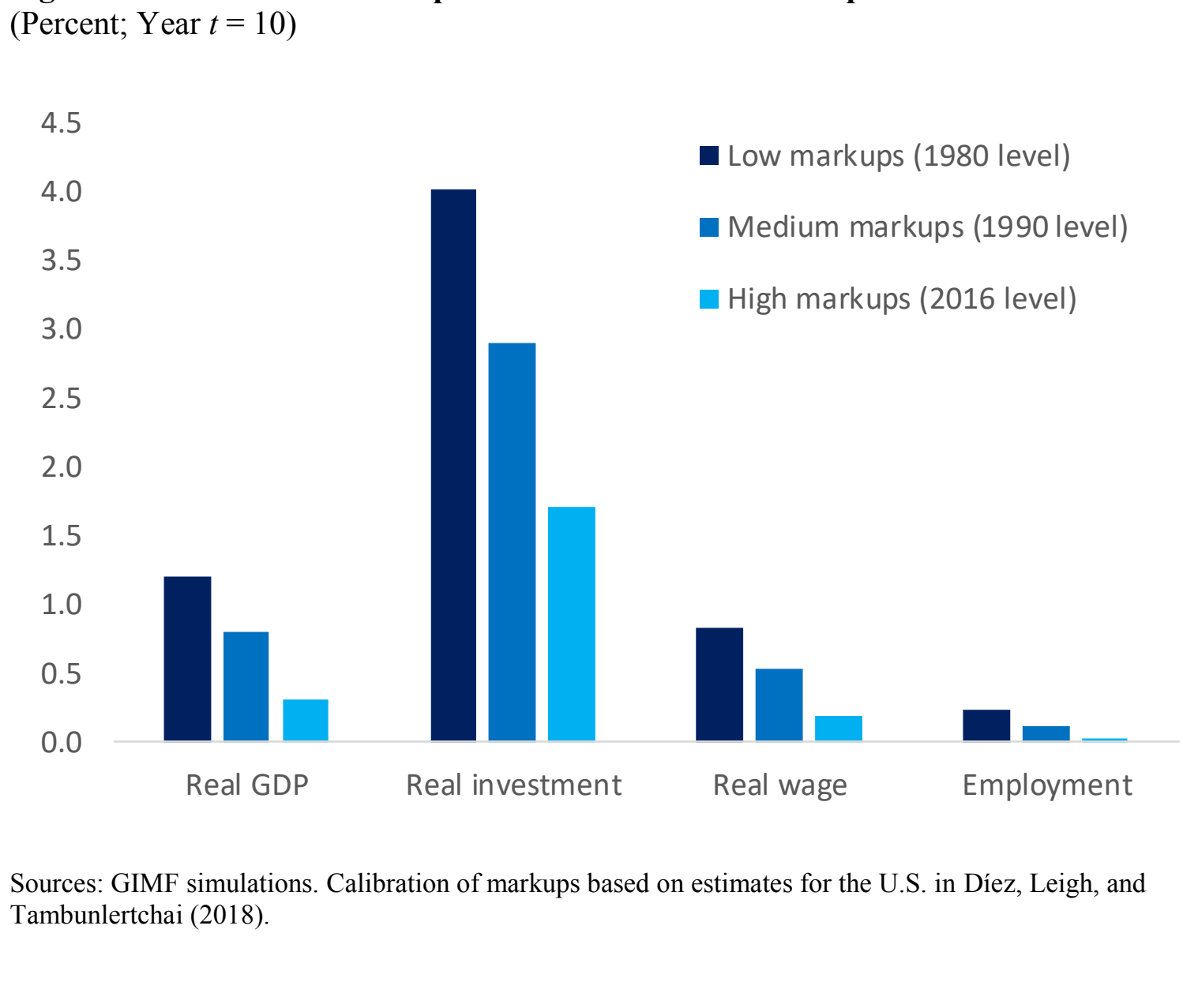


Figure 14. Estimated Effect of Tax-based Fiscal Expansion of 1 Percent of GDP vs. Markup
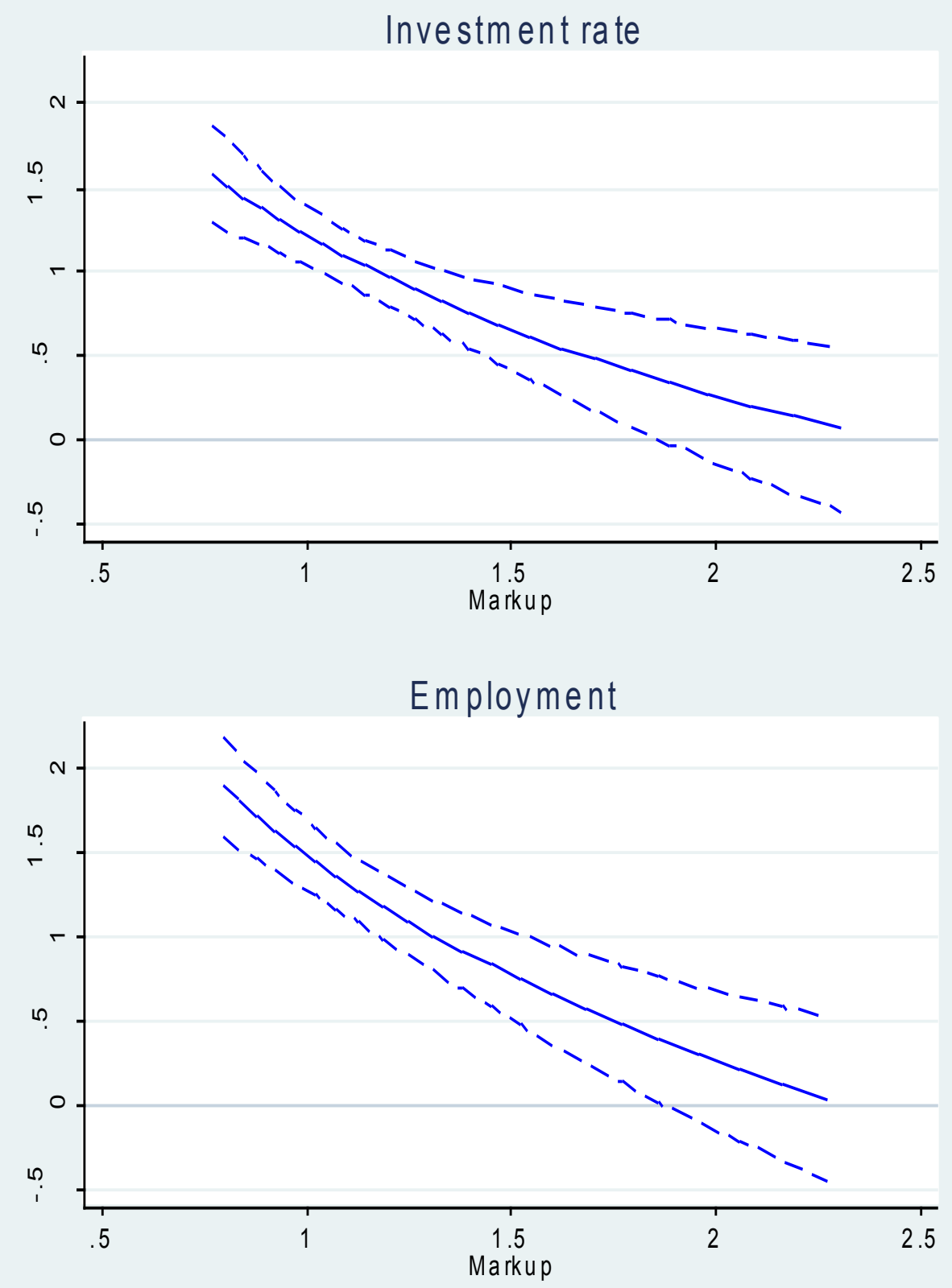
Figure 15. Predicted vs. Actual Growth of Business Investment in 2018

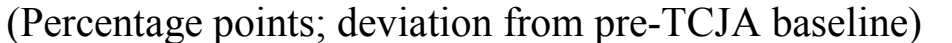
$\square$

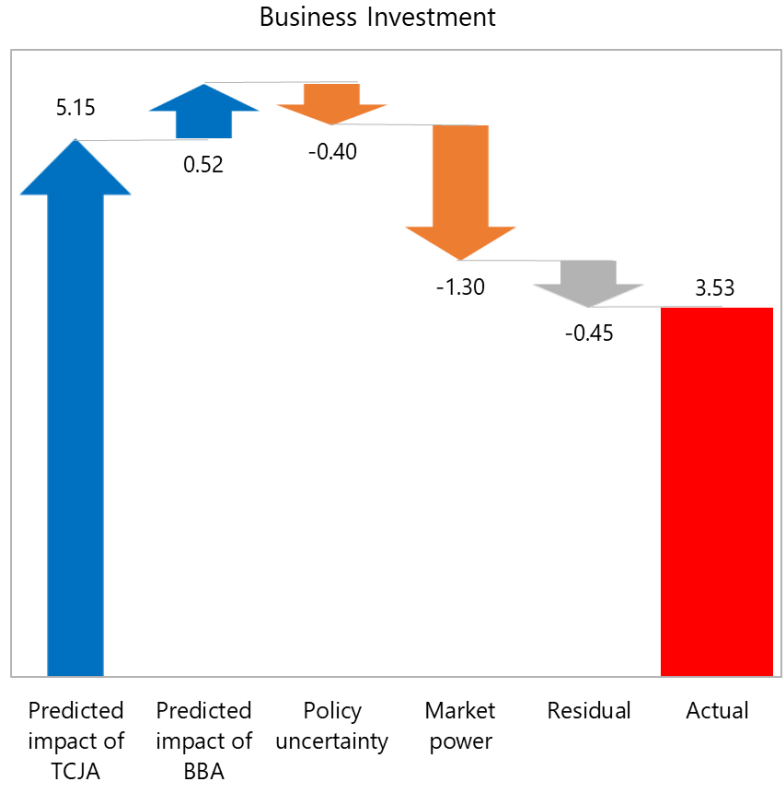

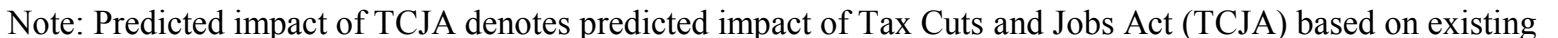

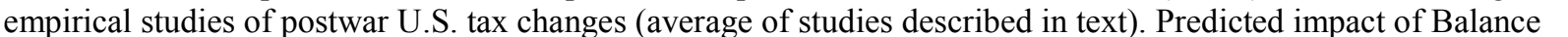

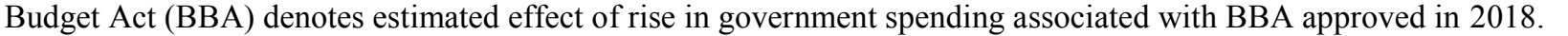

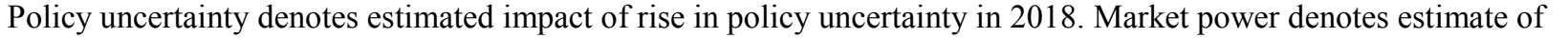
ए

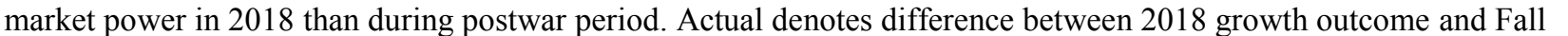

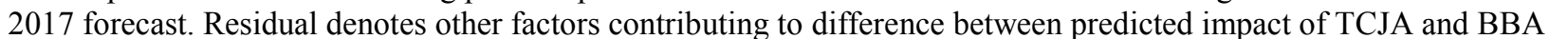

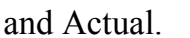


Table 1. Budgetary Impact of the Tax Cuts and Jobs Act

\begin{tabular}{|c|c|c|c|c|}
\hline Provision & 2018 & 2019 & 2020 & 2027 \\
\hline Total & -0.7 & -1.4 & -1.2 & 0.1 \\
\hline Individual Tax Reform & -0.4 & -0.9 & -0.8 & 0.3 \\
\hline Pass-through tax cut & -0.1 & -0.2 & -0.2 & 0.0 \\
\hline Other & -0.2 & -0.7 & -0.6 & 0.3 \\
\hline Business Tax Reform & -0.6 & -0.6 & -0.5 & -0.2 \\
\hline Reduction in CIT rate (35\% to $21 \%$ ) & -0.5 & -0.6 & -0.6 & -0.6 \\
\hline Expensing of capital spending & -0.2 & -0.2 & -0.1 & 0.0 \\
\hline Other & 0.0 & 0.1 & 0.2 & 0.3 \\
\hline International Tax Reform & 0.3 & 0.2 & 0.1 & 0.0 \\
\hline \multicolumn{5}{|l|}{ Memorandum } \\
\hline Pass-through and $\mathrm{CIT}$ rate cut & -0.6 & -0.8 & -0.8 & -0.6 \\
\hline
\end{tabular}

CInternational Monetary Fund. Not for Redistribution 


\section{Table 2. Estimated Effect of Tax-based Fiscal Expansion of 1 Percent of GDP on Firm} Investment and Employment $\square$

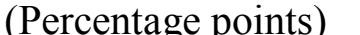

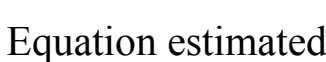

$$
Y_{i j k t}=\beta \Delta F_{k t}+\gamma\left(\Delta F_{k t} \times \ln \mu_{i j k t}\right)+\sum_{x} \theta_{x} x_{i j k t}+\sum_{i} \alpha_{i}+\sum_{t} \theta_{t}+\epsilon_{i j k t} \square
$$

\begin{tabular}{|c|c|c|c|c|c|c|}
\hline & \multicolumn{3}{|c|}{ Investment rate } & \multicolumn{3}{|c|}{ Employment growth } \\
\hline & (1) & $(2)$ & (3) & (4) & (5) & (6) \\
\hline Fiscal shock & $\begin{array}{c}1.218^{* * *} \\
(0.108)\end{array}$ & & & $\begin{array}{c}1.487^{* * *} \\
(0.126)\end{array}$ & & \\
\hline Fiscal shock $\times$ markup & $\begin{array}{c}-1.374 * * * \\
(0.389)\end{array}$ & $\begin{array}{c}-1.117^{* * *} \\
(0.420)\end{array}$ & $\begin{array}{c}-1.406^{* * *} \\
(0.416)\end{array}$ & $\begin{array}{c}-1.756 * * * \\
(0.392)\end{array}$ & $\begin{array}{c}-0.700 * \\
(0.424)\end{array}$ & $\begin{array}{c}-1.048^{* *} \\
(0.429)\end{array}$ \\
\hline Firm FE & Yes & Yes & Yes & Yes & Yes & Yes \\
\hline Time FE & Yes & & & Yes & & \\
\hline Country $\times$ time FE & & Yes & Yes & & Yes & Yes \\
\hline Industry $\times$ time FE & & & Yes & & & Yes \\
\hline Number of observations & 204,251 & 204,251 & 204,251 & 190,207 & 190,207 & 190,207 \\
\hline R-squared & 0.074 & 0.093 & 0.114 & 0.035 & 0.062 & 0.073 \\
\hline
\end{tabular}

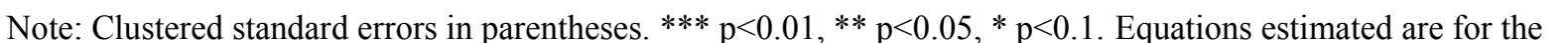

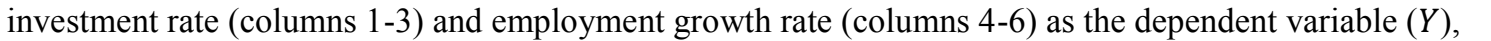

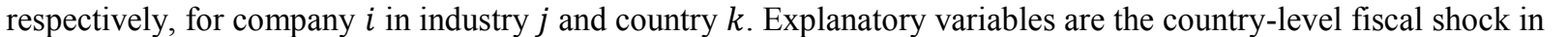

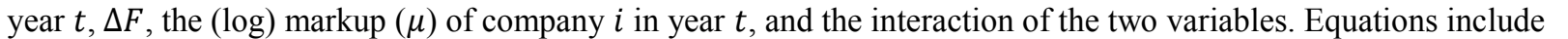
प

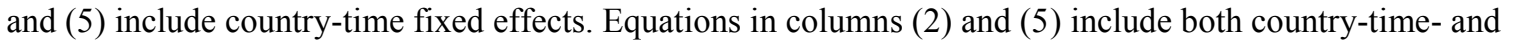

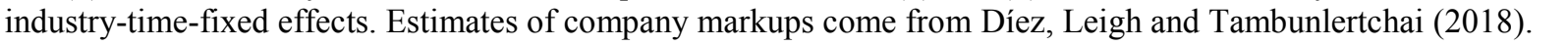

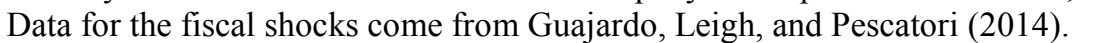

(CInternational Monetary Fund. Not for Redistribution 
Table 3. Cross-section Estimation Results: U.S. S\&P 500 Companies in 2018

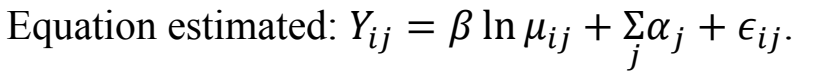

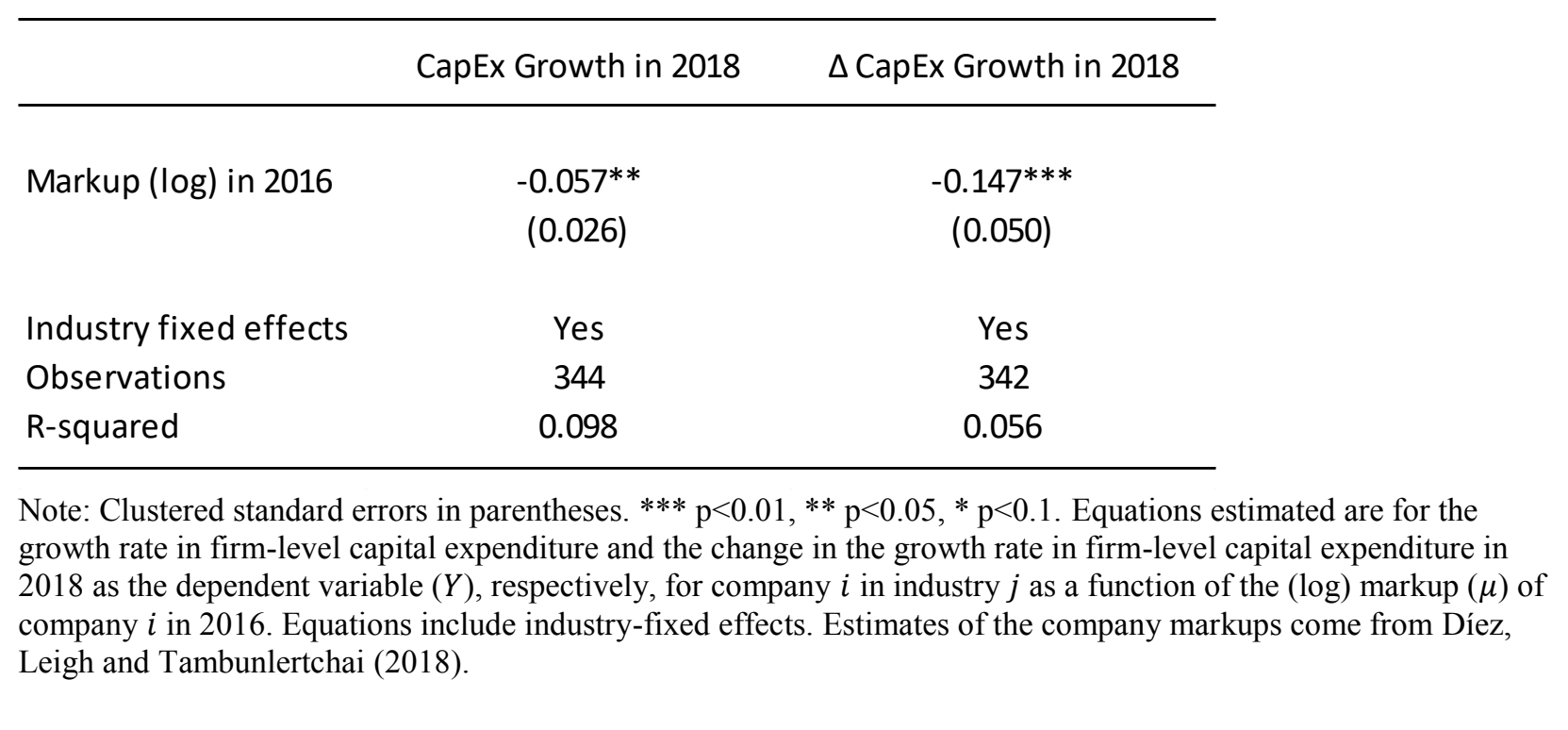

